\title{
Induction and Natural Necessity in the Middle Ages
}

\author{
Stathis Psillos \\ Dept of Philosophy and History of Science \\ University of Athens \\ \& \\ Rotman Institute of Philosophy \\ Dept of Philosophy, \\ University of Western Ontario
}

\section{Introduction ${ }^{1}$}

In Topics (157a8) Aristotle noted: "What sort of process induction is is obvious". Yet, he had already attempted to elucidate it by arguing that induction (epagoge) is "the

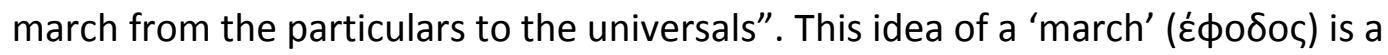
metaphor. It states how induction starts and where it ends, but how it gets there (to the universals) is not clarified. ${ }^{2}$

In fact, Aristotle spoke about epagoge in various places in his corpus, but he never offered a full and complete theory of it. There are scholars who argue that Aristotle's epagoge is something substantially different from what we nowadays call 'induction'; hence, they dismiss the claim that thinking about Aristotelian epagoge can cast light on the problem of induction. I think this is wrong. Aristotle knowingly introduced epagoge as a mode of inference in order to address a sharp philosophical problem, viz., how general principles can be known on the basis of experience. He therefore set the stage for all subsequent discussions of induction.

In this paper I will use as background Aristotle's account of induction in Posterior Analytics. This is because his treatment of induction in this treatise is clearly associated with the philosophical problem of the status of first (necessary and general) principles of episteme (science). But my aim is not to explicate Aristotle's theory (though I shall offer an account of it). My aim is to discuss in detail the major theories of induction as these were presented, developed and defended in the Middle Ages in the Latin West. In particular, I will start with Aquinas's views on induction and then discuss the theories of Duns Scotus, William of Ockham, Jean Buridan, Nicolaus of Autrecourt and Pseudo-Duns Scotus).

Induction played a major, but changing, role in the conceptions of scientia in the middle ages-especially after the re-discovery and translation into Latin of the

\footnotetext{
${ }^{1}$ This study is part of a bigger project aiming to unravel the conceptual history of induction. I would like to dedicate it to Dionysis Anapolitanos, former colleague, close friend and philosophe extraordinaire.

${ }^{2}$ All references to Aristotle are from (1984).
} 
Posterior Analytics. It seems that Boethius did translate Aristotle's Posterior Analytics into Latin, but this work was lost. Aristotle's treatise started to be discussed only after it was translated into Latin by James of Venice between 1125 and 1150 . The first commentary of the work was by Robert Grosseteste (1175-1253), written around 1230. One of the key subsequent commentaries was Thomas Aquinas's.

With the changing conceptions of induction there were changing conceptions of scientia - that is, of the kind of knowledge that was taken to characterise the knowledge of nature. Most importantly, induction and its justification as a means to arrive at universal and necessary truths were backed up by a certain metaphysics of nature, which grounded induction in the presence of natural-but not metaphysical-necessities. These natural necessities, in their turn, were grounded in the natures of things and their essential properties. This 'inflated' metaphysics of nature was the major characteristic of the Aristotelian-medieval conception of nature.

Though induction was rooted in experience, it was taken to be justified as a means for knowledge of first principles by the operation of the intellect. Yet, there were different and competing conceptions of the role of the intellect and rival views about the principles that are required for a knowledge-producing induction. The common denominator, as it were, of all such views was that inductive scepticism was not an option. ${ }^{3}$ And yet, there were significant differences as to how inductive scepticism was avoided. The gap that was opened between principles that were naturally necessary but metaphysically contingent made it possible either to make room for a kind of knowledge which is characterised by natural and not by absolute certainty (Buridan) or to doubt that there can be knowledge of naturally necessary principles on the basis of experience (Autrecourt). This possibility of doubt made room for a form of inductive scepticism, mostly in the form of a doubt that induction can deliver knowledge as opposed to opinion or conjecture. Throughout this period, at stake was a move from a strict Aristotelian conception of scientia to views which allowed forms of knowledge without certainty.

Drawing the complex terrain of the theories of induction and of the various ways to ground inductive knowledge will be the aim of this paper. There have already been two excellent attempts to draw this terrain. The first is by Julius $R$. Weinberg (1965) and the second by E. P. Bos (1993). My attempt differs from theirs in two major respects. The first is that it is more detailed in the examination of the various theories and their relations. The second is that I focus on the role of natural necessities in induction. In particular, I try to place the various conceptions of induction within a network of issues that relate to the problem of universals, natural necessities and a power-based approach to activity in nature.

Here is the road map. Section 2 explains Aristotle's views of induction, as this were mainly developed in Posterior Analytics Book II.19 and states what I take it to

\footnotetext{
${ }^{3}$ For a number of perspectives on scepticism in the middle ages, see Lagerlund (2010).
} 
be the main dilemma of induction, as this was described by Sextus Empiricus: induction is either perfect and impossible or imperfect and unjustified. In section 3, I move to Thomas Aquinas and his own attempt to justify induction and the actuality of general and necessary principles based on experience by an appeal to the natural light of reason. In section 4 I discuss John Duns Scotus's reliance on a self-evident maxim to bridge the gap between imperfect and perfect induction. Section 5 moves to William of Ockham's peculiar attempt to justify single-instance inductions. Then, section 6 offers a detailed account of Jean Buridan's ground-breaking reconceptualisation of induction and the role of intellect in it. Section 7 discusses the critique of induction by Nicolaus of Autrecourt. Finally, section 8 offers a brief account of Pseudo-Scotus's move from knowledge to opinion.

\section{The Background: Aristotle and Sextus on Induction}

According to Aristotle's conception of knowledge, episteme-the kind of knowledge that characterises science-is demonstrative and causal knowledge that starts from first principles. Of these first principles, Aristotle said that they are "true and primitive and immediate and more familiar than and prior to and explanatory of the conclusion" (71b19-25). Aristotelian first principles, besides, are general principles, as they involve relations among universals and they hold of everything to which the universals apply. For a universal $P$ to hold of every object $x$ (of a certain kind) it should be the case that $\mathrm{P}$ holds for all $\mathrm{xs}$ at all times and at all places. An Aristotelian universal is an one over the many particulars (that is, it is shared by many particulars), but (unlike Platonic forms) it is not one apart from the many. An Aristotelian universal ontologically depends on particulars in that it would not exist if there were no particulars ( $a k a$ individual substances). (2b5-7)

Universals are middle terms in a demonstration (and hence, in the Aristotelian account of demonstration, they capture the causes of whatever should be causally explained). So if there are no universals, there are no middle terms; there is no demonstration; hence there is no scientific knowledge. It should be stressed that, for Aristotle, all scientific knowledge worthy of the name is general knowledge (of the universals) and not knowledge of particulars: a particular object c has property $B$ (or belongs to the kind $B$ ) in virtue of the fact that it shares with other particulars attribute $A$ and All As are B.

Aristotle also thought that first principles - the principles on which, ultimately, all scientific knowledge rests-should be necessary principles in the sense that they are such that the property attributed to the subject (an Aristotelian principle has typically the form: All As are B; or better A is B) could not be otherwise: it is necessarily possessed by the subject. Necessity is, for Aristotle, a sure way to generality. If the connection among the universals captured in a principle is such that it cannot be otherwise, if that this, A cannot but be $B$, then it follows that All As have 
to be Bs; and hence that All As are Bs. That is, there is no possibility of exceptions. The principle, then, is truly and genuinely general. Here is how Aristotle put it:

we all suppose that what we know is not capable of being otherwise; of things capable of being otherwise, we do not know, when they have passed outside our observation, whether they exist or not. Therefore, the object of knowledge is of necessity (1139b19-24).

So, episteme for Aristotle is both general and necessary. Demonstration, Aristotle says, is a deduction "which depends on necessities" (74b13-17). Famously, Aristotle also thought that experience is a source of knowledge and that, in particular, knowledge starts with perception. How then can first principles themselves be known?

Aristotle wants to exclude two possible answers to this question. The first is that the knowledge of first principles (of which he never doubts) is innate; the second is that first principles are known on the basis of prior demonstration (e.g., they are derived from other known propositions). Obviously, the second answer would lead to an infinite regress. A third option, it seems, for the knowledge of first principles is experience. In Posterior Analytics, Aristotle takes perception ( $\alpha i \sigma \theta \eta \sigma \iota \varsigma)$ to be awareness of particulars common to all animals. But for experience, memory (i.e., the ability to retain a percept) is also required. Actually, for Aristotle, experience requires the presence of many memories of the same thing. And beyond this, experience involves a universal, which as Aristotle says, "comes to rest in the soul" (100a6). Experience, for Aristotle, is already general in that through it a universal (a concept, one might say) is lodged in the mind. So we can say that Aristotle takes experience to be quite a complex state which involves both perception and memory in such a way that experience of $x$ be constituted by the stable and repeated memories of perceived instances of $x$. But how, if at all, can experience lead to knowledge of first principles?

Epagoge is a process by means of which first principles come to be known (100b3); a process, that is, which is not deduction (proof) and yet produces knowledge (but not episteme) of first principles. Induction proceeds on the basis of particulars and is not possible without them (81a40).

Aristotle is adamant that episteme cannot be gained through perception. But if perception of particulars is required for knowledge, and if induction proceeds on the basis of particulars aiming to "hunt" (as Aristotle 88a3-4 put it) the universal in them, it follows that epagoge plays a key role in acquiring knowledge-but not epistemeof first principles, with the dual character of generality and necessity. Even though Aristotle does not quite tie induction with enumeration of instances, he does insist that it is by viewing repeated instances that we view the universal: "it is from many particulars that the universal becomes evident" (88a4).

It seems we face a conundrum: epagoge is indispensable in getting to know the first principles, but epagoge does not yield episteme. In the closing chapter (B19) of 
Posterior Analytics, Aristotle introduces the technical word 'nous' to capture the state (hexis) in which one is in when one knows first principles. Nous is to induction what episteme is to deduction. First principles become known via induction, and the "state which gets to know them" is nous: "it is by induction that we get to know the first principles, since this is the way perception instils universals" (100b3-4). But nous (in the technical sense of the world) is one thing, and episteme is another. Strictly speaking there is no episteme of first principles, even though the first principles are known: they are known via induction and the state of knowing them is nous. Hence, Aristotle puts forward a two-tier account of scientific knowledge: once the first principles are in place, demonstration rules; but the first principles themselves are known via induction. Since, however, first principles are known, induction is not in any way inferior to deduction when it comes to knowledge; it just leads to a different kind of (non-demonstrative) knowledge, captured by the technical word 'nous'.

This is an important move. Non-demonstrative knowledge (that is, knowledge based on induction) is no less knowledge than demonstrative knowledge (based on demonstration) and is required by demonstrative knowledge, since the knowledge of the first principles is non-demonstrative. Non-demonstrative knowledge is knowledge of general and necessary truths based on experience. But in B19, Aristotle does not describe how exactly induction works. He merely sketches how it is based on the perception of particulars. Things become worse since English renderings of 'nous' have included expressions like intuition and rational insightand this may create (and has created) the impression that Aristotle took it to be the case that after induction has operated by perceiving (repeated) particulars, some further process or faculty (intuition; rational insight) is required for getting to the first principles. This is not correct. Though this is hardly the place to go into Aristotelian exegesis, the method by means of which the first principles are arrived at is epagoge (induction), though the state of knowledge we are when the first principles are known is not episteme, but as Jonathan Barnes had translated 'nous', comprehension.

Aristotle saw in induction an uncontested method by means of which general and necessary principles are generated and adopted. He clearly thought that this must be possible, since otherwise episteme itself would not be possible. Recall that the first principles (being general and necessary) are neither innate nor demonstrable. And though they are not derived from experience either by simple enumeration of instances, the process by which they are formed (induction) has its basis on experience; and in particular on the (repeated) perception of particular cases.

My claim is that Aristotle set the stage for what came to be known as the problem of induction, since his endeavours generated the following question: How possibly can experience lead to first principles which are universal and necessary (and certain and state the ultimate causes of things)? The problem bequeathed by Aristotle to his 
successors was precisely to explain how the method of science can bring under one roof generality and necessity on the one hand and justification or warrant on the other. $^{4}$

It seems that by the time of the Roman world and the early middle ages, induction was taken to be, by and large, generalisation from particular instances to a general statement or a move from many past instances to the next instance. So induction was increasingly taken to be based on an ineliminable element of enumeration.

When Sextus Empiricus (c. 160-210) systematised the sceptical approach to knowledge, he took it that induction (epagoge) is a reasoning process which returns a generalisation of the form All As are B on the basis of instances of the form a is $A$ and $a$ is $B$ (his example: 'All men are animals' is induced by instances such as Socrates is an animal; Plato is an animal etc.) But he was adamant that this method (of establishing the universal from the particulars) "totters" because it faces a dilemma. It will either progress on the basis of some but not all particulars, but then it is possible that there may be exceptions among those particulars not surveyed. Or, it will progress on the basis of surveying all (relevant) particulars, but this task is impossible, since the particulars are "indefinite and indeterminate". Hence, induction will be either uncertain or impossible (cf. 2000, Book II XV §204).

It is noteworthy that he took induction to be a mode of reasoning which purports to yield knowledge of the universal (something that we have already seen in Aristotle too) by enumerating particulars (something which Aristotle did not quite ascertain). The dilemma that Sextus poses is then quite forceful. For the transition from the (many) particulars to the (one) universal that they presumably share will always be 'shaky' (as Sextus put it) unless there is reason to believe that the particulars already surveyed are like the ones not yet surveyed. But what can the source of this reason be?

Sextus identifies what I will call the central dilemma of induction, as this was discussed after Aristotle: induction is either perfect and impossible or imperfect and unjustified (issuing only in plausibility). The very possibility of this dilemma requires, however, a shift from understanding induction as Aristotle did in Posterior Analytics to taking it to require a complete enumeration of instances. This is not an implausible thought. Aristotle, as we have seen, takes for granted that there is this mode of non-demonstrative reasoning which yields general and necessary principles based on the experience of particulars without requiring complete enumeration of instances-not even requiring that a lot of instances are necessary. But, one may think, how possibly can the universal be found from experience of particulars if there

\footnotetext{
${ }^{4}$ In my discussion of Aristotle I have not touched upon his conception of induction in Prior Analytics, Book II.23 (68b15-29) and in Topics VIII, 2 157a25. For an excellent discussion see McCaskey (2007).
} 
is no guarantee that all relevant particulars have been surveyed and 'fall under' the universal? ${ }^{5}$

\section{Aquinas and the role of intellect}

There is virtually no reference to induction in St Thomas's magnum opus: the Summa Theologica. ${ }^{6}$ There is a however an example which shows how Aquinas used induction in his own reasoning. In the first article of the Simplicity of God, (First part, Question 3) concerning whether God is a body, Aquinas argues against the bodily nature of God in three ways, one of which is based on induction. Here is how he puts it:

First, because no body is in motion unless it be put in motion, as is evident from induction. Now it has been already proved, that God is the First Mover, and is Himself unmoved. Therefore it is clear that God is not a body $(1947,31)$.

In this kind of argument, induction justifies the major premise of a demonstrative argument, viz., that no body is in motion unless it is moved by something else. By induction, in other words, it is proved that there is no self-motion. Since-the minor premise-God is the first unmoved mover, it follows that God is incorporeal. (For if he were not, he would be in self-motion.) From the example it is suggested that induction yields a universal generalisation based on the observation of individual cases (singulars, as he would put it) and that this way to proceed from the singulars to the universal principle is justified: it delivers premises for demonstrative arguments.

It is precisely this role that induction was supposed to play within the Aristotelian framework that shaped the medieval world view. In his Summaries of Logic, which was the first comprehensive introduction to Logic, written in the second quarter of the thirteen century and widely used and read for a long time, Peter of Spain (2014, 199) described induction, qua a species of argumentation, as follows:

Induction is moving from particulars to a universal like

Sortes runs, Plato runs, Cicero runs,

\footnotetext{
${ }^{5}$ There is an important part of the subsequent discussions that I will not present here so that this study stays at relatively manageable length. Cicero (106-43BC), who introduced the Latin term 'inductio' as a translation of 'epagoge', took induction to be a form of argumentation which moves from facts which are not doubtful to facts which are doubtful "on account of their resemblance" (De Inventione, Book I). Views about induction were expressed by Boethius and various commentators of Aristotle, most importantly Alexander of Aphrodisias and John Philoponus. An important transformation of the role of induction took place among the Arab commentators of Aristotle, in particular in the work of Ibn Sina (Latin 'Avicenna'-980-1037). He made an important distinction between induction (epagoge; istiqra) and what has been translated as 'methodic experience (empeiria; tajriba). For detailed discussion see McGinnis (2003).

${ }^{6}$ All references to the Summa are from (1947).
} 
and so forth for each one (et sic de singulis);

therefore, every man runs.

Aquinas himself presented his account of induction in his commentary of Aristotle's Posterior Analytics. He cited Aristotle's claim that induction is one of the two ways to acquire knowledge, the other being demonstration (cf. Lecture 30, Chapter 18) and he noted:

But these two ways differ, because demonstration proceeds from universals, but induction from particulars. Therefore, if any universals from which demonstration proceeds could be known without induction, it would follow that a person could acquire scientia of things of which he does not have sense experience. But it is impossible that universals be known scientifically without induction.

So for Aquinas, as for Aristotle, experience is necessary for the knowledge of universals. Moreover, induction is non-demonstrative; induction is based on experience; and induction is required for the knowledge of universals, which are required for demonstration. Hence, induction is not just one of the two ways of acquiring knowledge; it is an indispensable way to acquire it. There could be no scientia, if there were only demonstration.

Following Aristotle's conception of episteme, scientia was taken to be a special (and perhaps ideal) state of knowledge-but one which, for Aristotle's medieval followers-captures what it is for knowledge to be scientific. It is knowledge which is certain, universal and necessary. Aquinas notes that "a person who has scientia of something knows that it is impossible for it to be otherwise" (Commentary to PA, n.d, 551). Induction, as it was typically conceived, delivered truths which were universal and necessary.

It is a significant development in the middle ages that there is a distinction between two kinds of necessity-one absolute (I will call it metaphysical necessity) and another relative ( $\mathrm{l}$ will call it, following most medieval thinkers, natural necessity). The distinction has mostly to do with the fact that there is a new player in medieval thinking, viz., God. As Simo Knuuttila, Jaako Hintikka and others have made clear, the ancient (Aristotelian) account of necessity, by and large, identifies necessity with universality. They have called this, the statistical account of modality. According to it, "what always is, is by necessity, and what never is, is impossible" (Knuuttila 1990,191). Hence, a property which belongs to all members of a species is a necessary property. To be sure, this account of modality was grounded to the Aristotelian idea of potency or power, viz., the claim that accidents (properties in general) are active (and passive) powers which are posited to explain and ground change and motion in nature. For the present purposes, suffices to say that without denying this power-based account of modality, Aquinas (and Albert the Great before him) felt the need to draw a distinction between what is necessary according to the 
natural order of things and what is possible for God. God does not act of natural necessity. God acts out of his own will: "His will is the cause of all things" (Summa, Part I, Q25, art5; 1947, 320).

God, according to Aquinas, does create (and preserve) the "natural order of things", that is the order that characterises the action of the secondary causes in nature. But God can do something outside the natural order. He can produce the effects of secondary causes without them; or he can produce effects which secondary causes cannot produce. Hence, God can act 'supernaturally' -meaning: outside the natural order. Hence, though something might be naturally necessaryviz., necessary according to the natural order of things - it is not metaphysically necessary: God can choose to violate the natural order and perhaps reveal himself by means of a miracle. ${ }^{7}$

Natural necessity, then, is a characteristic of nature. It is, to be sure, an impression from God: God fixes the nature of things and they tend towards their ends. Still natural necessity is based on the "action of nature" - what can happen is "what actually takes place". And, as noted already, it is contrasted to absolute or formal necessity (Summa, Part I, Q82 art2; 1947, 920). Here is how he put it:

The word 'necessity' is employed in many ways. For that which must be is necessary. Now that a thing must be may belong to it by an intrinsic principle-either material, as when we say that everything composed of contraries is of necessity corruptible-or formal, as when we say that it is necessary for the three angles of a triangle to be equal to two right angles. And this is 'natural' and 'absolute necessity.'

Aquinas, arguably, still retains the statistical account of necessity-but he restricts it to the natural order. And, he also accepts the Aristotelian idea that natural necessity is grounded in the natures and powers of things. He draws a distinction between two senses of possibility (and a forteriori, of necessity):

a) "in relation to some power". That is,

If $X$ has the power to bring about $Y$, then $Y$ is possible (for $X)$.

b) "absolutely" or based on the relation in which the terms of a proposition stand to each other. That is,

\footnotetext{
${ }^{7}$ Here is a relevant quotation: "If therefore we consider the order of things depending on the first cause, God cannot do anything against this order; for, if He did so, He would act against His foreknowledge, or His will, or His goodness. But if we consider the order of things depending on any secondary cause, thus God can do something outside such order; for He is not subject to the order of secondary causes; but, on the contrary, this order is subject to Him, as proceeding from Him, not by a natural necessity, but by the choice of His own will; for He could have created another order of things. Wherefore God can do something outside this order created by Him, when He chooses, for instance by producing the effects of secondary causes without them, or by producing certain effects to which secondary cause do not extend" (Part I, Q105, Art 6; 1947, 1155).
} 
If $X$ and $Y$ are incompatible, they are not co-possible.

Given the prevailing idea that propositions have subject-predicate form, a claim of the form ' $\mathrm{S}$ is $\mathrm{P}$ ' is absolutely possible if "the predicate is not incompatible with the subject"; whereas it is absolutely impossible "when the predicate is altogether incompatible with the subject". But then, naturally necessary truths are not absolutely impossible.

What kind of necessity then is there in the principles arrived at by induction? When it comes to the principles that characterise the natural world, there can be only one kind of necessity, viz., natural necessity. The first (and not just the first) principles of science-insofar as they are principles of the natural order of things, grounded in their natures and powers-are not absolutely necessary: denying them does not entail any contradiction and God could certainly (if he so willed) render copossible some combination of events that is denied by a naturally necessary principle-e.g. the resurrection of Lazarus. Recall the example of motion noted above. Aquinas says: "a natural thing is moved through the power of its mover by a natural necessity" (Summa Part II, Q104, art 5; 1947, 3738). If this principle, viz., that whatever moves is moved by something else, is established by induction, induction establishes a naturally necessary truth. And in fact, this can only be established by induction.

But how can induction deliver (naturally) necessary truths? Aquinas, following Aristotle, contrasts induction to syllogism-that is, demonstration. The latter is such that the conclusion of necessity follows from the premises - as he eloquently states. And it is clear that induction cannot become a syllogism unless complete enumeration is feasible. So the conclusion of an induction cannot necessarily follow from its premises - viz., the singulars - unless there is complete enumeration. But this does not imply that the inductively arrived at principle cannot be naturally necessary. Of course, the inductively arrived at the general principle is not demonstrated; it is non-demonstrably true. But this is as it should be, given that it is arrived at by induction.

Aquinas took it that the universal is 'over and above' the particulars, but not apart from them. How is this to be understood? In Lecture 20 of his Commentary to PA, Aquinas takes Aristotle to suggest that the universal is one outside the many not because it has an independent existence (esse) but in virtue of the intellect, which considers a nature, e.g. human, without referring to particular human beings, e.g., Plato, Socrates, etc. But even though the universal is one outside the many as considered by the intellect, it exists in all singulars as one and the same-not numerically, as if humanity was numerically one in all men, but according to the notion of the species. Accordingly, Aquinas advances the view that universals exist within the particulars, though they are considered by the intellect as being without 
the particulars, that is a being species which can be thought of without having any specific particular of this species in mind. Still, what is shared by the particulars is not a numerically one universal. Rather, particulars belong to species and they belong to a certain species because of their likeness. As Aquinas explains, this white and that white are similar in whiteness but they do not share one numerical whitenessexisting in both. Similarly, Plato's humanity is similar to Socrates's humanity though it is not a numerically one humanity shared by both, that is existing in both. ${ }^{8}$

As is well-known, Aquinas took common natures to be universals. Species and genera, as he put it in the Summa (Summa Part I, Quest 30, art 4; 1947, 367) characterise the common natures of particulars; but common natures exist "only in individual matter" (Summa, Part I, Quest 4, art 4; 1947, 121). So as Eleanor Stump has put it, for Aquinas "universals exist only in the mind" $(2003,44)$. As Aquinas explains in Summa (Part 1, Quest 12, art 4; 1947, 121), common natures (species) are "abstracted" from particulars "by the considering act of the intellect" and hence it is through the intellect that we can conceive of an object as belonging to a species. ${ }^{9}$

If particulars are like or unlike each other in virtue of their particularised natures, then induction is the process by means the universal "rests in the soul", that is, the universal is conceived by the intellect as something - a common nature-shared by many particulars, without the intellect having in view any particular in particular.

\footnotetext{
${ }^{8}$ Here is the relevant quotation: This universal is said to be resting in the mind, inasmuch as it is considered outside the singulars, which undergo change. Furthermore, he [Aristotle] says that it is one outside the many, not according to an autonomous existence but according to the consideration of the intellect which considers a nature, say of man, without referring to Socrates and Plato. But even though it is one outside the many according to the intellect's consideration, nevertheless in the sphere of existents it exists in all singulars one and the same: not numerically, however, as though the humanity of all men were numerically one, but according to the notion of the species. For just as this white is similar to that white in whiteness, not as though there were one numerical whiteness existing in the two, so too Socrates is similar to Plato in humanity, but not as though there were numerically one humanity existing in the two.-) the principle of art and science is formed in the mind." (Commentary to PA, n.d., 555).

${ }^{9}$ A few paragraphs later in his Commentary to PA, (n.d., 557), Aquinas present a slightly modified account of universals, which seems consistent with a stronger view, viz., that universals are numerically one shared by the singulars. He says: "Then (100a4) he [Aristotle] elucidates something asserted in the preceding solution, namely, that the universal is taken from experience bearing on singulars. (...) For if many singulars are taken which are without differences as to some one item existing in them, that one item according to which they are not different, once it is received in the mind, is the first universal, no matter what it may be, i.e., whether it pertains to the essence of the singulars or not. For since we find that Socrates and Plato and many others are without difference as to whiteness, we take this one item, namely, white, as a universal which is an accident. Similarly, because we find that Socrates and Plato and the others are not different as to rationality, this one item in which they do not differ, namely, rational, we take as a universal which is an essential difference." Now, the important part of this passage, I think, is that the process of having universals resting in the mind-and hence the process of forming principles of science-is the same irrespective of whether or not the universal is essential or accidental. This implies that induction is ubiquitous and delivers general principles simpliciter. Can this passage be read as suggesting that the universal is numerically one over the many? I doubt this because Aquinas stresses-again - that the universal is one over the many "once it is received in the mind".
} 
This common item, Aquinas says, is fixed in the soul, which now considers it "without considering any of the singulars" (Commentary to PA, n.d., 555). This is how, he says, "the principle of art and science is formed in the mind" (Commentary to PA, n.d., 555).

This kind of process - the conception of the common nature-is ubiquitous in science. It is by means of this process that principles such as "such a species of herb heals fever absolutely" are taken to be rules of science, based on experience and in particular on repeated experiences of instances of resembling cases-e.g., of this herb curing Socrates's fever and Plato's fever and other people's fevers.

If it were to be suggested that the process described is not induction, it would be enough to reply that for Aquinas this is exactly what induction does: "For that is the way, i.e., by way of induction, that the sense introduces the universal into the soul, inasmuch as all the singulars are considered" (Commentary to PA, n.d., 558). But this does not imply that all the singulars have to be enumerated. The intellect considers all the singulars through the universal, but it does not have to go to the universal via enumerating all of them. The intellect knows the universal through abstraction from sensible similarities and differences in the particulars.

Let me elaborate a bit more on this. In Posterior Analytics, Aristotle uses the rather cryptic metaphor of the battle to illustrate how perception instils universals in the soul. He says that the knowledge of universals comes from perception: "as in a battle, when a rout has occurred, first one man takes a stand, then another one does, and then another, until a position of strength is reached. And the soul is such as to be capable to undergo this" (100a10-15).

This is a notoriously difficult passage. I take it to suggest that the universal distils the pattern among the particulars. After a disorderly retreat in a battle, a soldier takes a stand, and then another, and soon enough there is a formation of soldiers which is now visible and effective. (Note that Aristotle says that the process carries on 'until a position of strength is reached' and a not until all retreating soldiers have a place in the formation.) There could be no knowledge of the formation without knowing the positions of at least some soldiers and this knowledge of the positions is based on experience. But the formation that the soldiers constitute (the universal, so to speak) is perceived too. And it is perceived even if not all soldiers have taken their positions. This simile suggests that it's not necessary that we survey all particulars to see the pattern. Actually, after having seen some particulars and the pattern, we can tell why the other particulars are the way they are (the rest of the soldiers take up the positions they should).

Commenting on the battle metaphor, Aquinas (Commentary to PA, n.d., 556) notes the following analogy: "So, too, from the sense and memory of one particular and then of another and another, something is finally reached which is the principle of art and science, as has been stated". This might suggest that Aquinas takes induction as enumeration. Yet, he immediately adds that "the mere remembrance of 
particulars" is not "sufficient to cause intellectual knowledge of principles". For this, the intellect is indispensable since this "makes things intelligible in act by abstraction of universals from particulars" (Commentary to PA n.d., 557).

In an important piece published in 1909, Fr Raymond noted that the method that Aquinas was trying to canvass may be called 'generalising abstraction'; better put, Aquinas took generalising abstraction to be a form -the proper form-of induction. I think there is some truth in this claim. Induction was viewed as an essentially abstractive process and abstraction was the means to bridge the gap there is between an ideal-but impossible-perfect induction and a real-but implausibleimperfect induction. One way to put the point is that imperfect induction was rendered perfect, that is, it was completed, with artificial means-and in particular with a process of abstraction which was supposed to move from the survey of a few (but not too few) particulars to the universal.

Albert the Great, Aquinas's teacher, had noted that though in a perfect induction all particulars are enumerated, in an imperfect induction, those particulars which have not been surveyed are 'insinuated' in the expression 'and so on for all the rest' (et sic de ceteris) (cf. Richard 1893, 306). But this is precisely the problem-viz., the status of the expression et sic de ceteris-and, more importantly, its justification. If induction is to deliver its goods - and it is imperative that it should-this clause should be scrutinised. For Aquinas, there is no doubt that there is no other way to first principles-and to general principles, in general-than induction. And there is no doubt that induction should be able to deliver knowledge because a sceptical stance towards it is not an option. As Aquinas put it, "Therefore, since we take a knowledge of universals from singulars, he [Aristotle] concludes that it is obviously necessary to acquire the first universal principles by induction" (Commentary to PA, n.d., 558).

That abstraction is involved in the forming the universal, and hence in induction, is something that Aquinas repeats often (Summa 1947 pp. 942, 961, 980). But how does it work? Aquinas renders Aristotle 'nous' as 'intellectum' but takes it that the intellect is conceived in a dual way. It is, as Aristotle thought, the state (hexis) one is in when one knows (that is, has non-demonstrative knowledge based on experience of) the first principles (cf. Commentary to PA, n.d., 559); however, he also takes it that the intellect has as its "function" to know the universal. Though this is not quite explained in the Commentary, in the Summa he says that the soul possesses two cognitive powers, one being the intellect (the other being related to the senses). It is in virtue of the act of the intellect that the universal is abstracted from the particulars and hence "it is through the intellect that we can understand [common natures] as universals" (Summa, Part I, Quest 12, art 4; 1947, 121). Given this understanding of the intellect, it is taken to be a special faculty of the soul which possesses the power of abstraction, the exercising of which distils the universal from the particulars. 
So Aquinas agrees with Aristotle that induction does not need enumeration, but he adds that it essentially rests on a process of intellectual abstraction. It is in this sense that induction is characterised as "the way that the sense introduces the universal into the soul, inasmuch as all the particulars are considered". Precisely because the soul cannot survey all the particulars and precisely because first principles are known and are known by reference to experience, Aquinas thought is that the soul must have a faculty (intellect) which views all the particulars of a kind, without enumerating them.

Significantly, this process of induction yields all kinds of (naturally necessary) principles. Here is his example: such a species of herb heals fever. This involves universals and is a principle. Entertaining it is based on particular instances, that is on Socrates's taking the herb and Plato's taking the herb etc; hence the principle could not be known without them; but the intellect considers the universal "without considering any of the particulars". According to Aquinas, repeated observations of instances (no matter how many they are) would still be at the level of experience; for them to yield a principle (and to be known as such) it is required that the intellect abstracts the universal from the particulars.

How can it be that the intellect has this abstractive power? In this commentary Super Boethium De Trinitate, (Question III, article 1) Aquinas commented briefly on "sufficient induction" as "that which inclines the mind to assent to the first principles of understanding or to conclusions known from these principles". But he takes it that the first principles are known by the natural light of reason: "Naturally possessed light of the intellect causes assent to the first principles". This light is given to us by God himself; hence "the light by which those principles are known is innate". So, induction-based as it is on experience-offers to the mind the matter of the first principles, but knowledge of them is achieved by the natural light of reason which causes assent to them.

Recall the key issue that we took Aristotle to have bequeathed to posterity: how can induction bring under one roof generality and necessity on the one hand and justification or warrant on the other? Aquinas's way out was that there is a special faculty of the human mind - the natural light of reason-which does the trick. This special faculty bridges the gap between imperfect induction and a perfect one.

\section{Duns Scotus and the maxim of induction}

John Duns Scotus (1266-1308) distinguished between principles such that the intellect can know their truth "by its own power", that is principles whose knowledge is merely occasioned by experience and not caused by it, and principles whose knowledge arises from experience-by means of induction. Principles of the first kind are "evidently true" (Wolter 1987, 108), that is they are such that their truth is guaranteed by the conceptual connections there are between their terms. The principles whose truth the intellect can know by its own power are, ultimately, 
principles which cannot be denied without contradiction. When, for instance, the intellect acquires the terms 'whole' and 'part', by the very meaning of these terms and its own power to put them together, it knows ("without any shadow of doubt") that 'Every whole is greater than its part'.

This principle, and others like this, are universal propositions which are necessarily true-but they are not arrived at by induction. They are subject to what Scotus called abstractive cognition, that is a form of knowledge which "abstracts from actual existence" $(2010,581)$; hence it relies in no way on its terms applying to some particular thing. It is contrasted to intuitive cognition, which is knowledge of particular things and implies their actual existence. This can be knowledge of singular propositions, such as 'Socrates is white', or general principles such as 'this kind of herb cures fever'.

But how can it be that the some universal principles are known from experience? In Question 4 of his Questions on the Metaphysics of Aristotle, Duns Scotus raises the question of whether art is the fruit of experience, where he takes art to be knowledge of the "reasoned fact", that is knowledge of the reason why. In trying to answer this kind of question, Scotus develops his theory of induction. He agrees with Aristotle that all knowledge rests on either syllogism or induction $(1997, \S 65)$ and notes a certain problem that induction seems to face: the principles which are arrived at by induction "are better known than the singulars on which their induction is based" $(1997, \S 65,100)$. This is a problem, I take it, because according to Aristotle, the premises of an argument should be more known than its conclusion-and this is clearly something that he insisted on in the case of demonstration. But when it comes to induction, how can it be that the premises, being singular claims from the senses, are better known than the general principle which is arrived at by induction?

One reply to this problem that Scotus considers but rejects is that the intellect comes to know first the singular propositions and then (in a temporal sense) the principle that "is proved from induction". Scotus's reply is that knowing the singulars "is only the occasion of knowing the principle, but it is not the reason why it is known" (1997, §67, 100). Perhaps, as he says, induction "in a simple and unqualified sense" yields no proof, but only imparts "information". The principle, according to Scotus, is endorsed more strongly than "something singular arrived at by induction". If it is not necessary that induction "be taken (...) as a kind of argument", how can it lead to the principles?

Scotus's reply is this:

(...) from many singular instances together with this proposition: 'nature acts most often if it is not impeded,' [etc.] a universal conclusion follows. And if the cause cannot be impeded, the conclusion follows in an unqualified sense in all cases $(1997, \S 68,101)$. 
What, therefore, closes the gap between many singular instances and a universal conclusion is a new proposition, which as Scotus puts it, states that 'nature acts most often if it is not impeded'. As stated the principle is not quite clear, but as Scotus explains later on $(1997, \S 89,104)$, the new proposition states that "nature (...) is acting for the most part uniformly and orderly". This, he says, is a proposition that expresses a simple and certain fact.

Before we discuss this maxim (meta-principle), let us see how it is supposed to act. What Scotus suggests is that this kind of meta-principle transforms induction into a proper argument: the inductive conclusion (the natural principle) follows from the many singulars and the meta-principle in an unqualified sense. In other words, this meta-principle turns, in effect, an imperfect induction into a perfect one, without enumerating all singulars-and in this way it secures that general natural principles can be known on the basis of experience.

In other writings, Scotus makes this meta-principle more precise. Here is the most typical formulation:

\footnotetext{
As for what is known by experience, I have this to say. Even though a person does not experience every single individual, but only great many, nor does he experience them in all times, but only frequently, still he knows infallibly that it is always this way and holds for all instances. He knows this is virtue of this proposition reposing to the soul: 'Whatever occurs in a great many instances by a cause that is not free, is the natural effect of that cause.' This proposition is known to the intellect even if the terms are derived from erring senses (...) (Wolter 1987, 109).
}

This is a strong principle. In effect, it says that the invariant consequent of an entity (which is not a free agent) is the natural effect of this entity-that is, it follows necessarily from it. This principle is meant to bridge the gap between past repetition and exceptionless (and necessary) generalisation. In other words, it is meant to turn any imperfect induction into a perfect one, by supplying a reason to consider all unexamined or unexaminable instances as being alike with the ones already surveyed. For all practical purposes, MP-S offers a justification of the claim et sic de ceteris.

What is the justification of this principle? Here is Scotus's argument (as I understand it, anyway). A non-free cause cannot produce an effect some times and its opposite some other times - for a non-free cause is 'ordered' (better: 'ordained') to bring about an effect (this is exactly what it is for it to be non-free). A casual cause can produce an effect or its opposite, or no effect at all. Hence, a casual cause cannot (it is not ordered to) produce an effect most of the times. Hence if a cause produces an effect most of the time and it is not free, it is a natural cause (that is, not a casual cause). The effect of a natural cause, being an invariable consequence of this cause, is the "effect of this nature as such".

Let's call Scotus's meta-principle MP-S: 
MP-S: "the effect in many cases of a cause that is not free is its natural effect".

It should be obvious that this cannot be evidently true in the sense that it cannot be denied without contradiction. Hence, it cannot be absolutely necessary. But can it be grounded in experience? This is not possible either. How then does MP-S come to rest in the soul? How can it be that it is known by the intellect? I think the answer is that this kind of meta-principle expresses the very idea of a natural order. Though it can be denied without contradiction, it cannot be denied without also denying the very idea of a natural order; more specifically of the idea of natural necessity. Understanding its terms amounts to understanding the idea of natural necessity. It is in this sense, I think, that the intellect knows it and it is in this sense that it is selfevident. Scotus did challenge the Augustinian idea of special natural illumination and favoured the view that the intellect has a natural power to "combine and divide" (Wolter 1987, 126). Though God is the remote cause of all knowledge of principles, the proximate cause is the intellect and its power to understand the conformity there is between the terms of a proposition. In particular, the proximate cause of inductive knowledge is the intellect's grasp of MP-S.

However, induction, even strengthened with a principle such as MP-S, does not offer knowledge of the reason why-it offers only knowledge that. To make this clear, Scotus distinguished between two ways to proceed if one starts from observation of particulars.

The first is to start from experience but use a general principle which is known evidently; then one may rely on this principle to draw a conclusion, which though initially known only through experience, it is now derived from the first principle; and hence it is known with certainty. To illustrate this, he uses a case known from experience, viz., that eclipses of the moon occur frequently. According to Scotus the reason why this fact occurs is not known from experience (though the fact itself is known from experience), but has to be delivered by a demonstrative argument. In this case, there is a general principle known evidently: if something opaque is placed between a source of light and an illuminated body, it obstructs light from reaching the illuminated body (the body is partly illuminated). Then it is discovered by 'division' that the earth is such an opaque body placed between the sun and the moon. This procedure will yield demonstrative knowledge of the lunar eclipse-not merely through experience as before "the discovery of the [evident] principle".

The second way to proceed is suitable if a first principle cannot be known evidently. This is when we must satisfy ourselves "with a principle whose terms are known by experience to be frequently united" (Wolter 1987, 110). This is a case of genuine induction; it is essentially based on experience of repetition. In this case, the generalization (the first principle) is licensed by virtue of the maxim MP-S. Scotus notes that this maxim removes "uncertainty and fallibility" from the generalizationand it constitutes the ultimate degree of scientific cognition. As an example, he uses 
the following: "this herb of such species is hot". The thought is that the maxim MP-S would licence this generalisation on the basis of a plurality of instances. So the repeated observation of samples of herb $X$ that are hot, aided by the principle that "the effect in many cases of a cause that is not free is its natural effect", would license the conclusion that herb $X$ is hot. This is general and necessary principle which involves universals. But it is arrived at and known only via grasping the more fundamental principle-a principle of induction, as it were-MP-S.

MP-S, therefore, does yield infallible and certain knowledge of principles based on experience; and yet, it is knowledge that and not knowledge of the reason why. This has to be provided by proper demonstrative syllogisms, ultimately based on selfevident principles.

It should be stressed that induction cannot lead anywhere without a maxim such as MP-S. In Metaphysics, Question 4, §§21-23, Scotus stresses that it is not enough for knowledge of a principle (a principle that) based on experience to have knowledge of many instances and knowledge of no exceptions. These are not enough to yield the conclusion that something is the case "in all instances". This kind of reasoning, Scotus argues, could only conclude that something "is probably the case". As such it could only be an "occasion for producing art or science". To move beyond the occasion to the actual possession of even the lower degree of science, a principle such as MP-S is required. For it is this principle that makes it the case that what is observed in many cases, is "necessarily true in all". Hence, MP-S adds necessity to generality, when the latter is based on experience and induction.

Inductive knowledge of the fact is necessary for knowing the reason why the fact obtains. As Scotus explains in $\S 79$ of Question 4 of Metaphysics, the difference between an inexperienced person and an expert, who both lack demonstration of the cause of a fact, is that the inexperienced only believes that something is the case (e.g, that a certain herb is hot), whereas the expect knows the fact "with certitude and without doubt" and her knowledge is licensed by the principle that nature acts uniformly and orderly-that is by MP-S. As noted above, this is knowledge even if it is not demonstrative knowledge. Hence, for Scotus, induction does deliver knowledge with certainty and infallibility, but it cannot deliver knowledge of the reason why facts are the way they are (that is, of their causes).

We have already noted how causal knowledge proceeds from first principles via demonstration. But Scotus goes on to suggest a certain way by means of which the causes of certain effects can be singled out and be known. Suppose, he says, there is situation $A$ in which factors $B \& C$ are present and one wants to find out which is the cause of an effect $D$. Then the proper way to proceed is "to separate" the potential causes. If $B$ is found without $C$ and if $D$ follows from $B$ but not from $C$, then in situation $A, B$ is the cause of $D$. This is how the cause of a particular effect is known when "several are conjoined" $(1997, \S 70)$. Scotus discusses briefly several ways in which this method can fail. For instance, it may happen that $B$ and $C$ cannot be 
separated. More importantly, Scotus notes that this method can, strictly speaking, deliver only a negative conclusion, viz., that $C$ is not the cause of $D$, if $D$ can exist without $C$. But from the conjunction of $B$ and $D$ it does not follow that $B$ is the cause of $D$, for it may be that $B$ is the effect of $D$ or that both $B$ and $D$ are "two necessary effects of the same cause", as both light and heat are the effects of fire. Or it may be that though $B$ is a sine qua non for $D$, it is not sufficient for $D$; hence it does not produce the effect $D$, though it is required by it.

This kind of discussion suggests that causal knowledge, though possible, is far from trivial. Various assumptions need to be in place and satisfied for getting causal knowledge from experience - the mere association of two factors is not sufficient, as the case of common effects shows. But Scotus insists that the association of two factors (the presence of a regularity, so to speak) is necessary for causation and causal knowledge. Here is how he puts the point:

Also, given the case that in one instance you see $D$ follows from $B$ but not from $C$, you do not know this to be the case in all instances. (...) Therefore, you could never know that something is necessarily and per se the cause of the other, and thus you would know nothing [scientifically] (1997, §75).

Causal knowledge is general knowledge and hence its possibility requires moving beyond single (or a few) instances to a general proposition-e.g., the herb of this species cures fever. A maxim such as MP-S renders an imperfect induction into a perfect one and by doing so, it unites generality and necessity. A first-order principle arrived at by the aid of MP-S is universal and necessary-that is, naturally necessary. This means that a first-order principle arrived at by the aid of MP-S (e.g., that the herb of this species is hot) can be denied without contradiction. As we have already noted, Scotus takes it that first-order principles known by induction are characterised by the lower degree of science (that is of scientific knowledge). To make this more precise, Scotus argues that first-order principles known by induction describe the aptitudes various things have: what they can do-what they are capable of doing. Hence, the best we can get from experience is that, for instance, the herb of this species "is suited by nature" to be hot; that is, it has the "aptitude" for an effect (Wolter 1987, 111). Here is how Scotus put it:

For if an attribute is an absolute entity other than the subject, it could be separated from its subject without involving any contradiction. Hence, the person whose knowledge is based on experience would not know whether such a thing is actually so or not, but only that by its nature is it apt to be so.

The reference to the principle of non-contradiction is very important. Whatever can be conceived without contradiction is possible and, according to Scotus and most mediaeval thinkers, it is within the power of God to obtain. God, in other 
words, has absolute power. But there is also relative or ordained power; that is, the powers that natural causes have been ordained to have. These powers could be suspended by God, though Scotus thought that God does not interfere with the natural order of things. Ordained powers circumscribe the realm of natural, as opposed to absolute, necessity. But this distinction between absolute necessity and relative necessity creates a problem. If a principle like 'herb of species $X$ is hot' is not absolutely necessary - since it can be denied without contradiction - the "uncertainty and fallibility" which are removed by Scotus's MP-S are conditional on the absence of God's interference. It follows that induction, aided by MP-S, yields only conditional necessity and generality. And this is expressed by the locution 'herb of species $X$ is apt to be hot'; or by the locution 'herb of species $X$ is by its nature apt to be hot'. To render empirical-inductive knowledge 'aptitudinal' is, for Scotus, to mark the fact that experience can only lead to naturally necessary principles, which can be denied without contradiction.

In Scotus's case, an appeal to higher-order principles like MP-S aims to solve the basic dilemma of induction (induction is either imperfect and unjustified or perfect and impossible) by suggesting that induction can be imperfect and justified by means of a substantive principle. His claim is that there is a principle such that for every induction, it renders the inductive conclusion (a naturally necessary generalisation) justified. As we shall, this kind of approach is resisted by Buridan and Autrecourt. Buridan denies that there is a single principle, whereas Autrecourt denies that there is any such principle. ${ }^{10}$

\section{Ockham and single instances}

William of Ockham (c.1287-1347) is justly famous for his nominalism. He emphatically denied that common natures, or universals, are entities existing outside the mind. Besides, he stressed that knowledge does not require commitment to universals or species. Intuitive cognition, that is the kind of cognition that acquaints us with existing objects, does not require positing "anything outside the intellect and the thing known, and most of all, no species" $(2010,626)$. In particular, experience, which is a means for intuitive knowledge, does not lead to the positing of species. Although when one sees a white thing, one sees "whiteness to be in it", one does not see "a species intuitively". But could it be that positing species is necessary for abstractive cognition, that is for cognition which abstracts away from the existence or non-existence of objects? Ockham denies this by claiming that abstractive cognition, which immediately follows intuitive cognition, adds no further entity except the object and the act of representation. Abstraction, to be sure, does produce a universal, but this is a "fictive being" $(2010,630)$. Abstraction is a kind of "mental picturing" $(1990,41)$. Ockham conceives of the universal as a pattern (exemplar) which "relates indifferently to all the singular things outside the mind"

\footnotetext{
${ }^{10}$ For an overview of Scotus's philosophy, see Vos (2006).
} 
$(1990,41)$. As such, it can stand for (be predicated of) many singulars. Hence, the universal, though a fictum in reality, it is a thought-object.

If nothing exists in reality "unless it is singular" $(2010,629)$, how is general knowledge possible? For a start, Ockham notes that, properly speaking, natural science "is not about things, but about mental contents standing for things; for the terms of scientifically known propositions stand for things" $(1990,12)$. Hence, though the concepts of scientific propositions are mental entities (that is, thought objects as opposed to real objects), they stand for (they can be predicated of) many singulars. Their generality is precisely this indifferent relations to singulars that fall under them. Here is his example of a "scientifically known proposition": 'All fire is hot'. The subject, Ockham says, "is a mental content common to every fire, and stands for every fire. This is the reason why the proposition is called real knowledge [that is, knowledge concerning real things]" $(1990,12)$. In other words, there is no res communis shared by all fires. But the substantial predicate 'fire' applies to all and only fires.

In Summa Logicae Book III-3, chapter 31, Ockham characterises induction as "progression from singulars to the universals", following Aristotle's definition. A such it is a species of argument or consequence. As he notes, for induction it is required that "the same predicate" is in "both the singulars and the universals and that the variation is on the side of the subject". What does that mean? There are three kinds of variation on the side of the subject. ${ }^{11}$

a. A demonstrative pronoun in the singulars: this one runs, and that one runs and so on for all the singulars; therefore every man runs.

b. A demonstrative pronoun with the subject of the universal proposition: this white thing runs, and that white thing runs, and so on for all the singulars; therefore every white thing runs.

c. Proper names in the singulars: Socrates runs, Plato runs and so on for all the singulars; therefore every man runs.

In all cases, the subjects vary but they all fall under the same predicate (universal). In terms of the example of the fire above, it is natural to think that the generalisation 'All fire is hot' is formed thus: this fire is hot, that fire is hot, and so on for all the singulars; therefore every fire is hot. Hence, it is like the case $b$ above, where a substantial predicate 'fire' applies to all singulars.

Note (again) the clause 'and so on for all the singulars' (et sic de singulis). It is this clause that turns an imperfect induction into a perfect one; and hence, into a demonstration. As we shall see in the next section, it was Buridan who challenged this move most forcefully. For the time being, let us examine Ockham's account in a bit more detail.

\footnotetext{
${ }^{11}$ As Ockham explains in Summa Part I, §19, these three ways are different ways to refer to particulars. 'Socrates', 'this' (when pointing to Socrates) and 'this white thing' (when pointing to Socrates) all refer to Socrates-and in general to particulars.
} 
In Summa (Part III, Tractate II, chapter 10), Ockham stated that some principles are known only via demonstration, but others are known through experience-e.g. that every herb of a certain sort cures fever or that the moon is able to be eclipsed. The starting point of knowing principles through experience, Ockham says, is the senses - they grasp various sensible things, e.g., that a particular fire is hot. Then the intellect takes over and notes that this fact that was given by the senses has various consequences, e.g, that if a certain thing $X$ is brought near this particular fire, $X$ becomes hot. This is brought out by a certain counterfactual conditional: if $X$ had not been near the hot thing, $X$ would not have become hot. By this procedure, the intellect grasps this very proposition "evidently": "This hot thing heats". This is still a singular proposition. Its generalisation relies on a certain meta-principle:

MP-O: "when something agrees with one individual it can in the same way coincide with another individual of the same species".

Based on MP-O, the universal proposition is formed and accepted: "Every heat is capable of heating". The rationale for this principle is that "there is no reason why one heat should be more capable of heating than another" $(2007,167)$

The universal proposition arrived at by MP-O is modal. It asserts what something can do; or what something has the power to do. We shall see the significance of this in a moment. For the time being, let us note that MP-O plays a similar role with the maxim introduced by Scotus (MP-S above). It is taken to license a transition from something that holds of a member of a species to all members of the species: if this fire is hot, then all fires are hot. To be more precise, the argument is thus: This fire is hot; the heat attributed to this fire characterises all other individual fires; therefore every fire can heat.

MP-O renders an apparently inductive argument into a demonstrative one. As he explains in Ordinatio, Book I, Prologue, Question 2, article 2, the principle "everything acting in the same most specific species is productive of effects of the same kind" $(2007,225)$, acts as "an extrinsic middle term" which turns the argument into a demonstration. The example he uses is different, but the point is the same: "This herb cures such an infirmity". This, as the case of heat above, is something known from experience. But from this contingent truth which is "evidently known" there can be evident knowledge of a demonstrable conclusion, viz., that "every herb of this species cures". For Ockham "This herb cures, therefore every herb of this species cures" is a demonstrative truth "not through some intrinsic middle term, which when it is adjoined, will produce a syllogism, but through an extrinsic middle, namely, 'everything acting in the same most specific species is productive of effects of the same kind'. " MP-O does not turn induction into a syllogism, strictly speaking; and yet, it replaces an ordinary induction by a demonstrative argument. A little later, Ockham notes that a principle such as MP-S "is necessary and evidently known: 
whatever absolute, or properly following on the absolute, coincides in a particular, in each particular of the same kind something can coincide in the same way" (2007, 226). It is in virtue of this principle that we can conclude that "since this herb has such a quality that is the principle of curing such an infirmity, every such herb can have this quality".

The crucial difference between Ockham and Scotus is that for Ockham just one instance is needed-no repetition or frequency is necessary for a general principle. Actually, this is the case only when infima species are concerned; that is, ultimate species for which there is no further differentia (the most specific natural kinds). As Ockham explains in Summa Part I, §21, a species is predicable of many individuals, and an infima species is predicable only of individuals.

Ockham intends to argue that an infima species "can be evidently cognized through the knowledge of one singular proposition" - that is, by knowing the essential properties of a single specimen $(2007,167)$. This is not so for the genera. Since there are many species in a genus, Ockham argues that a particular of each species is required for the cognition of the generalisation about the genus; hence several particulars are required.

It is no surprise that Ockham describes the transition from several species to a genus as induction $(2007,226)$. For the acceptance of a species-related generalisation amounts, actually, to demonstration from a single instance which possesses an essential property, via MP-O, to the proposition that all members of the species possess this property. But the acceptance of a genus-related generalisation requires the enumeration of all the species that fall under the genus and (at least) one instance of each species. A genus-related generalisation would require a principle such as "whatever coincides with something contained under a genus, it coincides in every case with that genus". Let's call this MP-O'. Ockham claims that this principle "will be received through experience and in a way through induction" (2007, 225). Far from being self-evident, MP-O' is an empirical principle. Here is his example: "Every human being can grow, every donkey can grow, every lion, and so for other particular cases; therefore every animal can grow". Note that this is an induction; it relies on the clause 'and so for other particular cases'. This clause might well turn an imperfect induction into a perfect one, but according to Ockham, in the case of genera the clause 'and so for other species' has an empirical grounding, being, in effect, a way to express MP-O'.

The rationale for asking just a single instance of an infima species in the case of a species-related inference would be easy to grasp, if the thought was that an infima species has an essence shared by all its members. If this were so, then a single member of the species would be an 'essential representative' of all other members-hence, a single instance would be enough. If, in other words, all members of an infima species share the same essential properties, then, if a certain essential property is known to be possessed by a certain individual, it is possessed by 
all individuals of the same kind. But as we have seen, Ockham denies that there are common natures or essences of the species. Actually, he denies that the species is anything substantial. How, then, can he claim that the members of an infima species are such that the essential property of one of its members is the same as the essential properties of the other members?

As Paul Vincent Spade (2000) has noted, Ockham does not deny that there are individual substances and individual qualities. Actually, apart from these 'things', not much else is posited. Ockham allows predicates - which stand for concepts and not common natures - to be applicable to various individual substances. As he explains in Summa part 1, $\S 22$, the species is not in the particular, but it is predicated of many particulars. The species is the genus plus the differentia. The latter is predicable of one species and not of others. As Ockham says: "it is called the essential difference not because it belongs to the essence of a thing but because it expresses part of the essence of a thing and nothing extrinsic to it" (Summa, part 1, §23; Loux 1974, 98). The difference is not a separate thing; it is not a real entity present in the species. Rather it can be predicated of one thing and not of another. Hence, differences are not essences qua separate entities, but individuals have, nonetheless, essential differences. These are always "concrete in form" but there corresponds to them general abstract terms. To use an example, the humanity of Socrates is distinct from the humanity of Plato, but they both fall under the predicate 'human being'. And they do so because of their similitude. The members of an infima species are alike each other and that is why the species is predicated of them. When Ockham says that they "agree essentially" he means that they are all alike: they have similar individual essences; that is they are similar individual substances, e.g., men, fires, or what have you (see Summa part I, §17; Loux 1974, 85-6).

Two important ramifications. First, Ockham admits that the single-instance inference is an ideal case. In most cases, many instances will be required. It is not easy to know from a single instance that this was not a spurious cause and that, instead, something else was the cause of a certain effect since "this species of effect could occur due to many distinct species of causes" $(2007,168)$. This move is meant to strengthen the evidence that an essential property has been identified. Second, the conclusion of the inference, the universal principle, is modal: A can cause (produce) B. As Ockham explains in his Summa Part 1, §24, a universal generalisation such as 'Every fire is hot' is metaphysically contingent. God could make a fire which is not hot; hence it is possible that the subject of the proposition exists, without having the property attributed to it. But a proposition such as 'Fire can heat' is necessary-it cannot be false, if something is a fire and does not cease to be a fire. This modal character of the principle leaves it open that, although $A$ can cause $B$, there may be $A$ without $B$, because $A$ is prevented to bring about $B$. The modal character of the principles, that is, grounds their natural necessity and allows that there might be exceptions to the actual generalisation. 
The key point that we have to keep in mind is that for both Scotus and Ockham experience is a source (necessary condition) for knowledge of general principles which nonetheless can be denied without contradiction, but experience (being in the form of observing frequent associations or even single instances) requires assistance from the intellect, which provides (and grasps) principles by means of which universal propositions are formed. These principles are meant to dissolve the basic dilemma of induction (recall: induction is either imperfect and unjustified or perfect and impossible) by making it the case that induction can be imperfect and yet justified by means of substantive principles.

\section{Jean Buridan on natural necessity and natural evidence}

Jean Buridan (1300-1358) was perhaps the first medieval philosopher to have developed a full and novel theory of induction and its justification. But what is induction? In Summulae de Dialectica, (Treatise 6, chapter 1, 6.1.3), Buridan characterises induction thus:

An induction is a reasoning from several singulars to the universal that has to be proved, as in 'Socrates runs and Plato runs ... and so on for the singulars; therefore, every man runs' (2001, 393).

The critical step, he thought is the "clause 'and so on for the other singulars". It is in virtue of this clause that, according to many, "an induction concludes formally and of necessity". As we have already seen, this view was going as far back and Albert the Great. In fact, the whole issue has been how to justify knowledge of this clause. But for Buridan this clause is "not an integral part of induction". What was the problem? Buridan considered two cases. The first is perfect induction, which proceeds with a complete enumeration of instances. This is feasible when the number of instances is finite and small. In this case the 'and so on for the singulars' is covered by the complete and explicit enumeration of the singulars. Perfect induction becomes a syllogism, since the universal principle is nothing but the conjunction of its instances. Here is how he put it:

I say 'over all [the singulars]' as when we say 'The moon does not twinkle, nor does Mercury, nor does Venus, nor does the sun, nor does Mars, nor does Jupiter, nor does Saturn; therefore, no planet twinkles', and then a reduction to syllogism can be performed as before, namely, by adding the minor that every planet is either the moon, or Venus, etc. $(2001,6.1 .5,399)$.

Hence, the clause 'and so on for the singulars' is not a proper part of perfect induction because a perfect induction is a syllogism in disguise. But rarely is the case that induction is perfect. In most cases, it is impossible to survey all particulars. Then the 'clause: and so on for the other singulars' has a bite. It seems that this clause would amount to an implicit enumeration of all the unseen instances, since it asserts 
that what holds of all the observed instances does hold for all the unobserved instances too. Hence, it seems that the clause 'and so on for the other singulars', in effect, turns an imperfect induction into a perfect induction, and by implication, to syllogism.

Not so fast, says Buridan. As he notes, the clause "and so on for the singulars" does not express a proposition; hence it cannot be used, as such, as a premise in a syllogism. But suppose, for the sake of the argument, that it does-what would this proposition be? If it is taken to be equivalent to the proposition "and all men other than Socrates and Plato", then if we were to add it to the other premises, (Socrates runs; Plato runs), the conclusion "every man runs" would clearly follow. But, says Buridan, the very statement "and all men other than Socrates and Plato" is itself a universal proposition. Hence the issue crops us as to how this is known. It cannot be taken to be established by induction, since this would be question begging (petitio principii). Could it be established by the intellect? If it were to be known by the intellect, the intellect could directly know the initial conclusion of the argument (that all men run), since, being universal, the proposition 'all men other than Socrates and Plato run' is not better known than the statement 'All men run'. Hence, if the intellect knew directly a universal proposition, the clause "and so on for the other singulars" would become irrelevant.

This is a sound argument that imperfect induction cannot become a syllogism by the addition of the clause 'and so on for the other singulars'. Any such attempt would be either question begging or would undermine the very need for the clause 'and so on for the other singulars'.

How about, then, trying to prove the clause 'and so on for the other singulars' in a different way? Here is what Buridan considers but rejects. Suppose that the intellect considers all unexamined instances (all humans other than Plato and Socrates) and finds no reason why they should be different from Socrates and Plato when it comes to running. Then the intellect "concedes" the clause "and so on for the other singulars' and concludes that every man runs. His ground-breaking objection to this way to proceed is that if the role of the intellect in induction is to look for a reason not to extend what has been perceived in the observed instances to the unobserved, or to look for a difference between the observed and the unobserved instances such that the property attributed to the observed instances cannot be extended to the unobserved, then induction does not have to rely on establishing the clause 'and so on for the other singulars'; nor any intermediate generalisation of the form 'and so on for all men other than Plato and Socrates'. Rather, the intellect, based on the absence of any reason to extent the property attributed to the observed instances to the unobserved, it moves directly to the generalisation that 'All men run'. This is a genuine induction, based on a re-conceptualisation of the role of the intellect in it. Here is how he puts the point: 
(I)t is not necessary in every valid induction to induce over all the singulars, for in many cases this would be impossible, since they are infinite to us; rather, it is sufficient to induce over many, and the intellect, on the basis of its natural inclination toward truth, perceiving no counterinstance in any of them, nor any reason why there should be a counterinstance in another, is compelled not only to concede that this is the case with them, but [it also has to concede] the universal proposition, which then becomes an indemonstrable principle, to be assumed in [the given] art or science without demonstration. For this is how we know the indemonstrable principle that every fire is hot, and that every magnet attracts iron, and that all rhubarb purges bile, and that everything that comes to be in nature comes to be from some preexisting subject, and so on for many other indemonstrable principles $(2001,396)$.

I claim that this is a ground-breaking conception of induction not because Buridan was right about the role of the intellect but because a) he took it that induction is a genuinely non-demonstrative mode of reasoning which yields naturally necessary general truths and $b$ ) the role of the intellect in it is not to look for a general metaprinciple which will justify all inductions. Buridan's re-conceptualisation of the role of the intellect is precisely that he denies that it acts via a general principle, such as Scotus's MP-S or Ockham's MP-O, which validates each and every induction and is itself known by the intellect with certainty. Rather, the intellect is an active principle itself, looking, in each and every particular induction, for reasons to make or do not make the inference from the particular observed instances to the a particular generalisation.

To be more precise, the intellect forms the generalisation that, for instance, every fire is hot not because it rests on a meta-principle which licenses the claim that all unobserved instances of fire are like the observed instances of fire, but because, guided by the experience of instances of fire, it has found no instance of a fire which is not hot, nor a reason to expect that unobserved fires are not (or will not be) hot. And the same holds for all other first-order generalisations, be they about magnets or herbs or rhubarbs, or what have you. In this process, induction remains a genuine non-demonstrative form of reasoning. Induction progresses from the particulars to the universal and this progression is licenced not by an extra premise (the clause "and so on for the other singulars") but by the intellect's natural inclination to truth. Here is how Buridan sums it up:

But if an induction cannot be performed over all the singulars, as in the case of our concluding from the singulars that every fire is hot, then such an induction is not reduced to syllogism, nor does it prove its conclusion on account of its being a formally valid consequence, nor because it may be reduced to a formally valid consequence, but because of the intellect's natural inclination toward truth $(2001,399)$.

According to Buridan's model, induction starts with the observation of particulars and the lack of counter-instances. How many particulars are required? "As many as would suffice to generate belief in the universal conclusion that is inferred", Buridan says $(2001,400)$. Then, the intellect "on the basis of its natural inclination toward 
truth" and lacking any reason to think that the unexamined cases will be different from the examined ones, infers (non-demonstratively) the universal proposition. This, Buridan asserts, is "an indemonstrable principle, to be assumed in [the given] art or science without demonstration".

What exactly is the intellect's natural inclination to truth? To address this question, let us place it in the context if Buridan's attempt to block scepticism, as this was developed in his Quaestiones in Duos Aristotelis Libros Posteriorum Analyticorum. ${ }^{12}$ One of the key sceptical positions against the possibility of scientia he tried to rebut was the following:

no <amount of > experience concludes in a universal proposition on account of its form, since no amount of experience can produce an induction <that includes> every singular. Therefore, it seems that principles are not certain (1.2. Question 2a, 10).

In his reply (\$14), Buridan distinguished between two kinds of evidence that can characterise scientia. Evidence "in the most proper way" is possessed by a proposition when the intellect, "by its own nature", is inclined to assent to this proposition and incapable of dissenting from it. However, there is a second kind of evidence possessed by "natural principles" and what follows from them. These principles can be denied without contradiction. Besides, the intellect could be deceived about them "by a supernatural cause". God, for instance, could make a fire without heat. Hence, the natural principle 'every fire is hot' cannot be known by the intellect by a kind of evidence of the first kind. But insofar as we stay within the "common course of nature", the intellect cannot be deceived about a principle such as the above-for it is part of the nature of fire to be hot. This kind of "natural evidence" - within the common course of nature-suffices for natural scientia.

This kind of distinction underwrites a double function of the intellect. The intellect can come to know some first principles independently of experience, by virtue of the relation of exclusion and inclusion that there are between their terms. These principles-the so-called "first mode principles", which correspond to nominal definitions, such as "man is an animal" - are like Scotus's principles of the first kind, which are known by the intellect's own power. But the intellect can come to know some first principles through experience though these principles "have natural evidence". For Buridan, taking "many experiences from a wide range of circumstances is never inadequate" as an aid to the intellect (§9). The intellect acts in the way we have already seen when we discussed his argument in the Summulae. Induction, "or inductive experience", does not conclude to a so-called "second mode" universal principle "in virtue of its form". Rather, in the absence of counterinstances and reasons to expect that there will be counter-instances, the intellect

\footnotetext{
${ }^{12}$ The Latin text of the Quaestiones and an English translation are given as an appendix in Economos (2009).
} 
"through its natural inclination toward truth, grants that a universal principle $<$ is $>$ known and evident through natural and possible evidence".

In 2.11 Question 11b (Whether knowledge of first principles is innate to us), Buridan takes up Aristotle's account of nous in Posterior Analytics B19 and draws the distinction between scientia and intellectus, where the latter is meant to capture the state (habitus/hexis) of knowing "first indemonstrable principles". Intellectus (which is typically rendered into English as understanding) is a state the intellectual power (that is the cognitive power of the intellect) is in 'in virtue of itself, as it has been determined by nature, just like fire is naturally determined toward burning if it comes into contact with a combustible thing". Hence, the intellectual power that results in understanding (and not scientia) of first principles is a natural disposition of the human mind which is naturally determined. In other words, unless something impedes the intellect, the intellect has a tendency-a tendency determined by its own nature-to understand the first principles. As noted already, this tendency or inclination does not need the aid of experience when it comes to first principles which capture nominal definitions - that is, principles which capture conceptual connections of inclusion or exclusion of terms (e.g. that white is a colour). But the tendency of the intellect to understand first principles requires the aid of experience when it comes to principles whose terms do not exclude or include each other (such as fire is hot). The intellect learns from experience that "this fire is hot" and "immediately" the intellect judges that fire is hot; and yet the intellect does not judge that "every fire is hot" until the intellect acquires experiences (and memory) of many fires being hot. Given this, when a fire "comes to mind", the intellect, based on past experience, will judge it to be hot, even though it has not yet been perceived. In other words, past repetitive experience conditions the intellect to expect that an unobserved fire will be hot. But the intellect has not thereby formed and understood the generalisation that every fire is hot. This genuinely inductive move takes place from the intellect's natural inclination to truth, when the intellect judges that there is no reason to expect that unseen fires should be dissimilar in this respect to the many and varied seen ones. The intellect "through its own nature is determined to concede the principle [that every fire is hot]; that is why it is called an "intelligible principle"".

Though Buridan agrees with Aristotle that the first principles are not innate but acquired, he claims that there is a certain virtue innate to us, "naturally inclining and determining <us> toward assenting to the truth of first principles if they are appropriately presented to [the intellect]". He repeats the analogy with the fire "which is naturally inclined toward burning when it is situated near a combustible thing", and he adds that "this innate virtue is human intellectus". I take it that Buridan considers the human intellect to be both an innate intellectual power which is characterised by a natural disposition towards truth and the state we are in when 
this power (on its own or aided by experience) is actualised and some nondemonstrative first principle is known (understood).

In Summulae Treatise 8, chapter 5, 8.5.4, Buridan describes essentially the same function of the intellect noting, significantly I think, that the intellect's natural disposition to assent to the first principles is analogous to the disposition of the swallow "to make such and such a nest when it is time to lay eggs". This strengthens the point that the intellect's disposition is a natural disposition, which is possessed by humans qua natural beings. But Buridan makes the further move to note that humans share with animals a certain estimative power (virtus aestimativa) to form judgements about the future based on the past. Suppose one sees a burning piece of coal, he touches it and it is hot. Then he views another burning piece of coal, he touches it and it is hot; "and the next day he sees another piece of burning coal, and then, remembering the others, he immediately judges that it is hot and hurtful, and avoids it." (2001, 722). Past experience leads him to form an expectation-actually a judgement-about fresh instances. However, Buridan seems to de-intellectualise this judgement ("it does not come about by means of the intellect"), since animals (even "a young puppy'), which do not have an intellect, are capable of making it. This judgement is not a perceptual judgement either, since there is no touching of the coal this time. Nor is it a judgement of memory, since it is not about the past, but about the present. Yet, it is a judgement of experience. It is on the basis of this experiential judgement that the intellect exercises its "natural inclination" to assent with "certainty and evidentness to the fact that this piece of coal is hot and harmful". This judgement is based on an indemonstrable principle of prudence.

As noted above, this judgement is not yet general-it concerns the next instance based on many past instances. The intellect is indispensably involved in the subsequent, generalising, step. It judges that since this piece of coal is hot, a piece of coal is hot. This last claim, viz. coal is hot (Carbo est calidus) is not yet general though it refers to any piece of coal; however, it is indefinite (about any piece of coal) and not singular (about this or that particular piece of coal). Then, by induction, the universal conclusion is drawn "that every piece of red, burning, glowing piece of coal is hot." It is here where the process we have stressed earlier kicks in. As he puts it:

For the intellect gathers from memory with certainty and evidentness that it knew many such pieces of coal to be hot by sensing them, and in none of these sensations did it perceive one not to be hot, and with careful consideration it perceives no contrary circumstance or reason why the case should not be the same with others. $(2001,723)^{13}$

The 'evidentness' that Buridan talks about here is not the same as the evidence of a truth which is licensed by the principle of non-contradiction: it is natural evidence.

\footnotetext{
${ }^{13}$ Zupko $(1993,209)$ presses the line that Buridan was a proto-reliabilist, because "the intellect, together with the evidence of sense, memory, and experience, is a reliable detector of the truth of propositions expressing second-mode principles".
} 
But it is a kind of evidence and it is such that increases the certainty of the universal principle. The inductively established universal principle removes the initial doubt of someone who "had never perceived fire or such coal". Induction, then, far from being impotent, removes the initial doubt from indemonstrable principles, by relying on experience and on the power of the intellect. As he put it: "a universal principle becomes known, recognized by, and evident to the intellect through induction, by the mediation of experience" (pp.723-724).

Buridan, we have stressed, does not take it that universal principles of science are absolutely necessary in the sense that their denial would lead to a contradiction. To accommodate their sui generis status, he introduced the idea of natural necessity. This is a kind of necessity which could be violated by God. As he put it: "There is another necessity which is called 'natural', which is not necessity simpliciter, but which would be necessity with all supernatural cases put to one side" (quoted by King 2001,16$)$. Hence, universal principles which are accepted by induction hold with natural necessity - so they are not necessary simpliciter. God could controvert them. But the possibility of God's intervention raises the following worry: How do we distinguish between a genuine counterexample to a principle and God's intervention to make an exception (e.g., a miracle)? A counter-instance could always be dismissed on the ground that it was an intervention from God and not an actual counterexample to the principle. I do not think there is an easy answer to this problem. My best shot comes from Buridan's claim that the explanation of natural phenomena should not rely on considerations based on divine omnipotence. Hence, if there appears to be an exception to an inductively established generalisation, this should be first and foremost accounted by natural, and not supernatural, means. Here is some evidence for it:

\footnotetext{
It must be noted that although the agent which is God can bring about each and every thing determinately and without anything else being determined, that action would not be called natural but miraculous. In natural actions, however, it must be the case that in addition to the universal agent, particular and determinate agents play a role in the fact that this rather than that happens, as when an agent fire determines the fact that a fire comes to be, or is produced, and not water, and the semen of a horse determines the fact that a horse is produced, and not a goat (QDA II.xo: 154, quoted by Zupko 1993, 215-6).
}

Buridan's ground-breaking point about induction is not so much that he did not rely on the idea of the natural illumination of the intellect; as we have seen this is something that Duns Scotus had already challenged. Buridan went beyond Duns Scotus by challenging the need for a single self-evident meta-principle which is taken to justify all inductions and which is known by the intellect. There is no single nondemonstrable principle that is itself justified and justifies all inductions. Rather, each and every induction yields an indemonstrable first principle, which is naturally necessary and known with natural evidence. The intellect does not employ a single 
maxim to justify the induction to unseen magnets, fires, rhubarbs and what have you. Moved by its own natural inclination to discover truths, it assents to each particular inductive generalisation by relying on the experience of many resembling instances and on the absence of a reason to think that unexamined instances (of fires, rhubarbs, magnets etc) will differ in the relevant respects from the examined ones. Whereas Scotus took it that there is a principle (MP-S) such that for each particular induction, the principle justifies it, Buridan reversed the quantifiers and argued that for each particular induction (be it about fires, rhubarbs, magnets or what have you), there is a principle such that the intellect comes to assent to the inductive generalisation. ${ }^{14}$ From a single indemonstrable principle, Buridan moves to a multiplicity of first principles, each arrived at, on account of the intellect's natural inclination to truth, by induction. ${ }^{15}$

In his excellent (1987), Peter King has argued that Buridan has described "the mechanics" of induction, without offering (or attempting to offer) a justification for it. Instead, King notes, Buridan asks the question "what is it to justifiably assent to [an inductive principle]"? He then claims that induction delivers truth under the common course of nature (CCN-truth), which is not truth simpliciter but "warranted assertibility". CCN-truth, King goes on, is "nothing but CCN-assent: assent to the principle on the basis of all the evidence open to us. Truth for physical principles just is warranted assertibility, and so the sceptic has no purchase on Buridan" $(1987,22)$.

It is certainly true that for Buridan natural principles, or principles of the second mode, are not true simpliciter, if by that we mean that they are true in virtue of being reduced to the principle of non-contradiction. Natural principles are not like principles of the first mode; they are true only within the common course of nature; that is, barring divine intervention. But it is not quite right to equate $\mathrm{CCN}$-truth with warranted assertibility if the latter is taken in its technical (Dummettian) sense, according to which warranted assertibility is evidence-constrained truth. For CCNtruths are not evidence-constrained truths; they go far beyond the actual evidence in being inductively established truths. A CCN-truth may be false if we were to go outside the common course of nature and conceive of God's interventions. But as King rightly notes natural principles "cannot even be said to be false simpliciter, for

\footnotetext{
${ }^{14}$ Zupko $(1993)$ takes issue with Thijssen $(1987,255)$ view that Buridan's "assumption of causal routines is in reality an a priori assumption", necessary "for maintaining the possibility of induction". Zupko argues that "the uniformity of nature principle" is not a first-mode principle, that is a selfevident principle $(1993,201)$, but a second-mode principle $(1993,202)$. My point has been that Buridan does nor rely on such a single and general principle. But it is true that this kind of principle, were to be used by Buridan, it would not be a first-mode principle. However, it could not be a secondmode principle either, since this would imply that this is known by induction from experience and hence its use in the justification of induction would amount to a petitio principii, of which, as we have seen, Buridan was fully aware.

${ }^{15}$ Grellard (2007) shows how Buridan arrived at the multiplicity of first principles thesis in an attempt to block infiinite regress arguments against demonstrative knowledge. The key idea, expressed in Summulae 8.5.2 is that since demonstrations have at least two premises, if an infinite regress in demonstration is to be stopped, there must be at least two non-demonstrative first principles.
} 
[natural] principle[s] are only CCN-true or CCN-false". Quite so. Hence, the real issue is: is $\mathrm{CCN}$-truth just $\mathrm{CCN}$-assent?

When Buridan claims that scientia requires "certainty and evidence" he adds that two other things are required too: "certainty of truth" and "certainty of assent" (Quaestiones 1.2 Question 2a, §13). The former is required because we could assent most firmly to a false proposition; the latter is required because a most certain and firm truth may be doubted. Hence, there is no scientia without truth; assent is not enough because it could be assent to a false principle. Now, Buridan's radical thought is that induction does deliver the first and indemonstrable principles of scientia. Hence, induction does deliver truths, albeit CCN-truths. Induction, then, cannot be just about justifiable assent to a principle. It should yield - and Buridan takes it that it does yield-justifiable assent to a true principle. Hence, CCN-truth is not $\mathrm{CCN}$-assent, though the latter is a reliable indicator of the former, if it is done in the appropriate way, that is based on past experience and the intellect's natural inclination to truth in the way Buridan has described.

So unlike King, and like Weinberg $(1965,153)$, I think Buridan does offer a justification of induction; but as I have stressed this is not via some supposedly selfevident universal principle that applies to each and every induction and licenses the inductive generalisation. Rather, each and every induction is justified by its own instances, the absence of counter-instances, the absence of any reason to think that in this particular induction the unseen instances are different from the seen onesand all this is licensed by a natural inclination of the intellect to discover truths about the world. One may doubt that the intellect possesses this inclination; but what cannot be doubted is that were it to possess it, inductions Buridan-style would deliver natural truths.

One last issue. Buridan was a card-carrying nominalist about universals. In what sense then are first principles general, if they do not involve universals? The key to answering this question lies in Buridan's abstractionism (cf. Klima 2009, 100-1). For Buridan, the intellect has the power of intellectual abstraction, viz., a power to extract essential information from resembling but distinct particulars, after acquiring sensory information of their resemblance. This is information that various resembling particulars "are of a certain kind". Hence, a certain kind-concept (a substantial concept) is predicated of all of them. Here is how Buridan describes this process:

Next, I again suppose that if there are any things similar to each other, whatever is a similarity for one of them, is, in the respect in which the two are similar to each other, a similarity for each of them. [...] Therefore, it follows from the fact that representation occurs by means of likeness that that which was representative of one thing will be indifferently representative of others [... ] From this it is finally inferred that whenever the species (and likeness) of Socrates has existed in the intellect and has been abstracted from the species of external things, it will no more be a representation of Socrates than of Plato and other men; nor does the intellect 
understand Socrates by it any more than other men. On the contrary, the intellect understands all men by it indifferently, in a single concept, namely, the concept from which the name 'man' is taken. And this is to understand universally (quoted by Klima 2009, 90-1)

The point here is that a single concept, which is abstracted from the likeness between Socrates, Plato and other humans, will be applicable to all humans indifferently and will represent any of them. It is this indifferent representation that grounds the universality of the concept. As as Buridan explains elsewhere some concepts are substantial (that is, they are concepts of substances) and the concept of man is one such concept. This is grounded on the fact that the corresponding term 'man' signifies human beings absolutely, that is as they are themselves and not in relation to anything else. It follows that the predication of human to Socrates is an essential predication in that Socrates is essentially a human as longs as he exists. But-and this is an important but-it does not follow from this that Socrates, Plato etc share an essence, a common nature and the like. In particular, it does not follow that there is anything like a universal, an one over all, or in all, the many particular humans, which is actually shared by the particular humans. What is posited is not an entity but a predicate, which is applicable to several particulars (humans) in virtue of their resemblances (in some degree or respect). As Klima $(2009,260)$ explains, Buridan was a predicate essentialist, and not a realist essentialist, in that he thought that some predicates apply essentially to various particulars, while others do not. In light of this picture, Buridan can claim that once the essential predicates applicable to individuals are abstracted by the intellect, they "necessarily apply to all individuals that fall under them as long as these individuals exist" (Klima 2009, 236). The inductive generalisations, then, employ such predicates and hence they 'cover' all individuals that fall under them without having to posit a universal distinct or separate from them. ${ }^{16}$

Induction is real and indispensable. It is on its basis that universal principles are known and justified. his answer to the basic dilemma (recall: induction is either imperfect and unjustified or perfect and impossible) is that induction can be imperfect and justified. But this is achieved not by means of a single general maxim but it is regulated by the intellect's natural inclination to truth.

\section{Nicolaus of Autrecourt and the principle of non-contradiction}

Despite their significant differences, the common denominator of all approaches so far is that there is no inductive scepticism. From the natural light of reason, to self-

\footnotetext{
${ }^{16}$ Peter King (2001) offers an excellent account on Buridan's nominalism. He too stresses the process of abstraction, stressing that "a concept produced by abstraction is equally a likeness of many items, and so indifferently represents them all" $(2001,16)$. Kings also emphasises that Buridan took it that externals things "have agreement and likeness among themselves in virtue of their nature and essence" $(2001,18)$. He notes that this amounts to admitting individual essences, but adds that this does not entail that that there is no common entity (a universal, a common nature) that individuals share.
} 
evident meta-principles, to the intellect's natural inclination to truth, the consensus is that the gap between imperfect induction and perfect induction is bridged: universal and necessary (that is, naturally necessary principles) are known on the basis of experience, though not by means of experience. But the very idea of a gap between metaphysical possibility and natural necessity-recognised by all medieval thinkers discussed so far-makes it possible for someone to deny-or questionthat there is this separate category of natural necessity and the concomitant claim that some universal principles hold with natural necessity though there is no contradiction in claiming that they are false. The possible falsity of a principle whose truth is based on experience makes room for questioning the status of the principles that are supposed to guarantee its truth. This room was occupied by Nicolaus of Autrecourt (1299-1369), a colleague of Jean Buridan in the University of Paris, who has been labelled 'the medieval Hume' (cf. Rashdall 1907).

Autrecourt recognized one kind of evidence. Evidently known is only whatever principle is reducible the law of non-contradiction. Hence, only whatever cannot be denied without contradiction is known. In his second letter to Bernard of Arezzo, Nicolaus lays out the consequences of this fundamental thought. The principle of non-contradiction (PNC) is the only first principle-there is no other principle which prior to PNC and PNC is prior to every other principle. PNC then is the standard of certitude. There are no degrees of certitude in knowledge: "the certitude of evidence has no degrees" $(2010,655)$. Given that PNC is immediately known by "the natural light", the certitude of natural light "is certitude in the unqualified sense". It follows that whatever is demonstrated from a principle by the natural light of reason, it "is demonstrated without qualification": the opposite of the consequent is not compatible with the antecedent. For Autrecourt, certitude in knowledge is incompatible with falsity-since PNC cannot be false. Here is how he puts it:

there is no certitude except that in which there is no falsity: because if there were any in which falsity could exist, let it be supposed that falsity does exist in it -then, since the certitude itself remains, it follows that someone is certain of something whose contradictory is true, without contradiction $(2010,655)$.

This is a critical point. Suppose that one knows with certainty that $P$, but it is possible that $P$ is false. If it is possible that a principle $P$ is false, then there is a circumstance $S$ in which $P$ is false. But in this circumstance $S$, one knows with certainty a proposition $P$ which is false. Since not- $P$ is true in $S$, one knows with certainty that $P$ though it is the case that not-P. Autrecourt's argument poses a dilemma: either certainty in knowledge is abandoned or certainty in knowledge implies necessary truth. Given that very few, if any, would opt for the first horn, Autrecourt's point is that they have to go for the second horn. But then, there cannot be certainty in knowledge with anything less than PNC-licensed truth. For any 
kind of 'necessary truth' which is weaker than one licensed by PNC, any 'naturally necessary' truth, could not be known with certainty.

Buridan, recall, does allow natural evidence or certainty. It is supposed to be grounded on relations of natural necessity. Autrecourt denies that there are such relations. Better put, he denies that we can ever have knowledge of relations of natural necessity. Take the statement "Fire is brought into contact with the fuel, and there is no impediment, therefore there will be heat" $(2010,657)$. In the context of medieval science, this is a typical case of a supposedly naturally necessary truth. Not so, for Autrecourt. For one, fire can be brought into contact with the fuel and there is no impediment, and still it is not contradictory to think that there is no heat. Autrecourt claims that the natural principle above does not have PNC-licensed evidence. The reason for this is not just that God could make a fire without heat. The reason is that there are no necessary connections of any kind between distinct existences. This is a crucial point. He states it thus:

From the fact that some thing is known to exist, it cannot be evidently inferred, by evidence reduced to the first principle or to the certitude of the first principle, that this other thing exist $(2010,655)$

What are distinct existences? If $X$ and $Y$ are such that $X$ 's existence implies $Y$ 's existence, then $X$ and $Y$ are not distinct. So the existence of the walls of a house is not distinct from the existence of the house since the existence of the house implies the existence of its walls. Here the wall is part of the identity of the house and hence they cannot be fully separate. But this is not the case when it comes to the fire which is brought into contact with the fuel and the heat. The heat is not part of the identity of the fire; hence it is not contradictory that there is fire without heat. Nicolaus backs all this up by noting that the very fact that a consequent follows demonstratively from an antecedent (and hence that it is impossible to have the antecedent without the consequent) is grounded on the fact that "the consequent is really identical with the antecedent or with part of what is signified by the antecedent" $(2010,655)$. This identity- or containment-account of consequence explains why there is no natural necessity which is not metaphysical or conceptual necessity.

But Autrecourt went on step beyond. In his second letter to Bernard of Arezzo, Autrecourt claimed that there cannot be any probable knowledge of alleged natural necessities; that is, there cannot be any knowledge of them on the basis of experience. His argument, as I understand it, is this. It is necessary for probable knowledge of $Y$ in virtue of $X$ that a person should evidently know (be evidently certain) that the consequent $Y$ "at some time will be true together with the antecedent" $X$. But a person cannot be evidently certain of this because from the things acquired without inference from experience, nothing can be evidently inferred about the existence of other things. In this argument, Autrecourt appeals to 
the "rule" he noted above, viz., from the fact that X exists nothing can be inferred about the existence of other distinct entities. His example of probable reasoning is instructive: "because it was at one time evident to me that when I put my hand in the fire I was hot, therefore it is probable to me that if I should put it there now I would be hot". This is an empirical inference from what has happened in the past to what will happen in the future-hence, it is an induction. But Autrecourt denies that this is a valid inference precisely because it should have never been "evident to anyone that, given these things which are apparent without inference, there would exist certain other things namely, those others which are called substances". Each hot fire is distinct from each other hot fire; hence, the appearance of one is no ground to infer the existence of others. 17

Could it be that the intellect could appeal to some self-evident principle such as Scotus's MP-S: "whatever occurs as in a great many things from some cause which is not free, is the natural effect of that cause"? In his Exigit ordo, Nicolaus closes off this possibility.

(O)nly opinion [habitus conjecturativus], not certainty, is had concerning things known by experience, in the way in which it is said to be known that rhubarb cures cholera, or that a magnet attracts iron. When it is proven that certitude [comes] from the proposition existing in the mind which states that what is usually produced by a non-free cause is its natural effect, I ask what you call a natural cause. A cause which has produced what has happened usually, and which will still produce in the future if [the cause] lasts and is applied? Then the minor premise is not known. Even if something has been produced usually, it is still not certain whether it must be produced in the future $(1971 \S 237,119)$.

The problem with Scotus's MP-S, as Nicolaus explains, is that it is question-begging. For to call $X$ the natural cause of $Y$, it must be that $X$ has produced $Y$ in the past and that $X$ "will still produce it in the future". But this (conjunctive) premise is not known. for it to be known it should be assumed that it is grounded on the principle of noncontradiction. But as Nicolaus states in the last sentence of the quotation, this is not possible. Differently put, Autrecourt's argument is this. The role of MS-S in a demonstrative argument would be the following:

\footnotetext{
${ }^{17}$ Here is the relevant quotation: “(...) a person does not have probable knowledge of any consequent in virtue of some antecedent, when he is not evidently certain whether the consequent will at some time be true together with the antecedent. For let anyone really consider well the nature of probable knowledge - as for example that because it was at one time evident to me that when I put my hand in the fire I was hot, therefore it is probable to me that if I should put it there now I would be hot. But from the rule stated above, it follows that it was never evident to anyone that, given these things which are apparent without inference, there would exist certain other things namely, those others which are called substances. It therefore follows that of their existence we do not have probable knowledge" $(2010,657)$.
} 
If $X$ is the natural cause of $Y$, then $Y$ follows $X$. (MP-S-major premise)

$\mathrm{X}$ is the natural cause of $\mathrm{Y}$. (minor premise)

Therefore, $Y$ follows $X$.

But how is it known that $X$ is the natural cause of $Y$ ? For $X$ to be the natural cause of $Y$, it should be the case not just that $Y$ has so far followed $X$, but that $Y$ will follow $X$. This cannot be evidently known; nor can it be known on the basis of experience. As Thijssen $(1987,249)$ states, Autrecourt's point is that "Scotus's maxim is merely verbal. It provided a definition of natural cause, but it is not possible to know when an agent will be a natural agent".

Could it be that there is a natural inclination of the intellect to truth, as Buridan has argued? Though Autrecourt does not say something explicit about this, he seems to imply that this is not a viable way to ground inductive knowledge either. For he doubts that "the intellect is the same for each human". For him, humans have different intellectual capacities, and since every faculty always works in its full power, it follows that it is not the case that all humans have the same intellect. I take it that it follows from this, that there is no universal (characteristic of all humans) natural inclination of the intellect to truth, since if there were such a universal inclination, there would be the same intellect in all humans.

Among the 32 propositions of Autrecourt's that were charged with being in error by Pope Clement VI in 1343 were the following:

Whatever conditions we take to be the cause of any effect, we do not evidently know that, those conditions being posited, it follows that the effect must be posited too (Rashdall 1907, 10).

We have no evident knowledge that there can be or is any efficient natural causes (Rashdall $1907,9)$.

We have no necessary knowledge whether any effect is or can naturally produced (ibid.)

Autrecourt's claim is that the alleged naturally necessary connections cannot be known. ${ }^{18}$ In fact, as he asserts "We know nothing of real efficient causes in the material world; God is the sole cause of every event" (Rashdall 1907, 9). This might imply that for Autrecourt, there is no such things as natural necessity. But there is some controversy as to how this point might be interpreted. Weinberg $(1948,66-67)$ takes it that it does not commit Autrecourt to occasionalism, but rather that he intends to make an epistemic point, viz., that God may be the sole agent.

Be that as it may, the point that needs to be stressed in that Nicolaus does not deny that induction is being relied upon in the derivation of general conclusions.

\footnotetext{
${ }^{18}$ The process of Nicolaus's condemnation was concluded in 1346; the inquiry was conducted by Cardinal Curty; a formal retraction took place on November 25, 1347.
} 
What he doubts is that it has what it takes to yield knowledge. Even if those who rely on "induction from some individual cases" think that the universal generalisation is "evident to them", it cannot possibly be objectively evident. For it is not objectively evident on the basis of observations of individual cases that even the observed individuals have the same nature, the implication being that it can be conceived without contradiction that they do not. Here is how he put it:

Sometimes, too, people say that something is totally evident to them which is evident only in part. For instance, someone states a universal proposition which he has accepted only by induction from some individual cases. Sometimes he proposes it by saying 'this is evident to me;' and yet nothing is evident to him except those singular propositions on which he based the induction; nor is it even evident to him that those singulars are of the same nature as far as the predicate is concerned $(1971, \S 234,115)$.

So what kind of state is the intellect in when a generalisation is arrived at by induction? It is a state of opinion-better, what he had described as conjectural habit (habitus conjecturativus). The observation of past cases of rhubarb curing cholera or of magnets attracting iron causes this conjectural habit that "rhubarb cures cholera, or that a magnet attracts iron". As Weinberg (1948 70, n.32) notes a conjectural habit is an "intellectual habit that is productive of conjecture". The past constant conjunction (e.g., of magnets attracting pieces of iron) produce the habit which, in turn, "produces a conjecture involving the universal character of the conjunction (op. cit.)

It should be pointed out that though, as we have seen, Buridan allowed for a multiplicity of first principles, each and every of them arrived at by a locally justified induction, licensed by the intellect's natural inclination to truth', Autrecourt allowed only one first principle, viz. PNC, as a principle underlying all certainty and all demonstrations. Hence, induction cannot possibly license knowledge with certainty of universal natural principles. But, interestingly, Autrecourt allowed that a multiplicity of universal natural principles can be subject to a conjectural habit.

Nicolaus's critique of induction was very telling. A common medieval assumption was that natural knowledge presupposes that natural processes are running their natural courses (ex supposition communis cursus naturae). And given this presupposition, inductive knowledge (that is knowledge of universal and naturally necessary truths) was taken to be actual. Nicolaus stressed that we can never know this presupposition since it is not grounded in the law of non-contradiction. Nicolaus did not have any significance influence to his contemporaries or his successors. It is noteworthy, however, that he anticipated some of Hume's criticisms.

\section{Pseudo Duns Scotus on probable opinion}

Before we close, it is important to note that a rather original treatment of induction comes from pseudo-Duns Scotus in his commentary of Aristotle's Prior Analytics. 
Until fairly recently, this work was attributed to John Duns Scotus but it is speculated that it was actually written by John of Cornwall (died after 1320) (cf. Bos 1993, 567). Though Pseudo-Scotus offers the typical Aristotelian definition (Induction is "the progression from the particulars to the universal") he is very sensitive to the issue of whether induction requires enumeration of all particulars or not. Is it the case that a "good induction" should consider "all the singulars"? (Question 8; Bos 1992, 81). ${ }^{19}$ Pseudo-Scotus says that "induction is unable to conclude of necessity unless it induces in all singulars". However, if the singulars are finite in number. then the conclusion is demonstrated: "Assuming that there would be no more than three men, namely, Socrates, Plato and Cicero, then it follows necessarily: Socrates runs, Plato runs, Cicero runs, hence every man runs. However, it does not follow evidently, unless this universal is added: all the men are Socrates, Plato, Cicero". The problem, as Pseudo-Scotus perceives it, is that an imperfect induction is such that the antecedent may be true and the consequent false (cf. Question 8, III.1; Bos 1992, 82 ). And this is so, since, according to a surprisingly modern reading of induction, it is possible that the attribute that is predicated to the observed particulars does not apply to the unexamined particulars; in this case the induction to the universal in the consequent might be false even if it is true of the antecedent.

Pseudo-Scotus very clearly points to the fact that induction is no demonstration, since the latter is such that the antecedent cannot be true and the conclusion false. Hence induction cannot produce "evidence" - which I take it to mean, in this context, certainty. Still (and significantly) Pseudo-Scotus thinks that imperfect induction can yield "probable opinion", which is sufficient for "faith or persuasion" of the universal conclusion (Question 8, III.3). And by means of this probable induction, the universal is acquired. It is this kind of imperfect induction that generates "the natural principles", such as that all fire is hot or that heavy bodies, if unimpeded, tend to fall downwards. How many singulars are required for an imperfect induction? Pseudo-Scotus claims that it is not possible to assign a certain number, but this will depend on the diversity the singulars in each particular case. The conclusion Pseudo-Scotus draws is that in the case of imperfect induction, the intellect is satisfied with less evidence than in the case of mathematics and that this is fine insofar as it stays within the "natural order" (Question 8, III.5).

\section{Concluding thoughts}

Induction in the middle ages was entwined with the thought that the world has a rigid metaphysical structure of natural necessities. Even nominalists did not deny

\footnotetext{
${ }^{19}$ All references are from Quaestio VIII (Utrum ad bonam inductionem oportet inducer in omnibus singularibus) in Pseudo-John Duns Scotus, Super librum secundum Priorum Analyticorum - reproduced in $\operatorname{Bos}(1993,81-85)$.
} 
this, though they took it that what grounds the generality and necessity of inductively arrived principles is not relations between universals qua res communis, but, ultimately, similarities and differences between individuals. But induction could not lead to knowledge of naturally necessary universal principles-and hence, induction could not reveal this rigid metaphysical structure-unless the intellect played an indispensable role in it. Once this role became to object of dispute, the sceptical challenges as well as weaker conceptions of evidence and knowledge started to become available.

Though they assumed an Aristotelian framework of scientia, the medieval philosophers developed complex and competing accounts of induction. They took it that induction is the way to universal and naturally necessary principles and aimed to show how what I called the basis dilemma of induction could be avoided-how that is, the gap between an imperfect induction and a perfect one can be bridged. Though induction requires the observation of particular instances, full enumeration was not taken to be necessary because the intellect was taken to fill the gap between examined instances and unexamined ones and to ground that the universal applies to the unexamined instances as well. How the intellect does that was a matter of debate: from the natural light of reason, to self-evident principles of inductions, to the intellect's natural inclination to truth. In all cases, the universal principle was naturally necessary: since the denial of a universal principle does not entail any contradiction, the principle does not hold with absolute necessity. But it was precisely this gap between natural necessity and metaphysical necessity that made possible the denial of the very idea of natural necessity, the only necessity being that which is governed by the law of non-contradiction. At the same time, the certainty by which the inductively arrived universal principles were known was qualified. Less demanding conceptions of scientia were developed and the very idea that there is only opinion or conjectural habit associated with induction became an option. $^{20}$

\section{References}

Aquinas, Thomas. 1947. Summa theologica. (Benziger Bros Edition. Translated by Fathers of the English Dominican Province) http://www.ccel.org/ccel/aquinas/summa.html

Aquinas, Thomas. n.d. Commentary on Aristotle's Posterior Analytics. (trans. by Fabian R. Larcher. e-edited and html-formatted by Joseph Kenny).

Aristotle. 1984. Complete Works of Aristotle. The Revised Oxford Translation, edited by J. Barnes. Princeton: Princeton University Press.

Bos, E.P. 1993. 'A contribution to the history of theories of induction in the middle Ages'. In: Jacobi K. (ed.) Argumentationstheorie: scholastische Forschungen zu den logischen und semantischen Regeln korrekten Folgerns. Brill, Leiden/New York, pp. 553-576.

\footnotetext{
${ }^{20}$ For more on this, see Pasnau (2010).
} 
Bos, E. P. 1992. 'Pseudo Johannes Scotus uber Induktion'. Historia Philosophiae Medii Aevi, pp. 71-103.

Buridan, John. 2001. Summulae de dialectica. trans. By Klima G. New Haven \& London: Yale University Press.

Duns Scotus, John. 2010. 'Intuitive and abstractive cognition'. In: Arthur Hyman, James J. Walsh, and Thomas Williams (eds) Philosophy in the Middle Ages, The Christian, Islamic, and Jewish Traditions (Third Edition). Indianapolis \& Cambridge: Hackett Publishing Company, Inc. p.581

Duns Scotus, John. 1997. Questions on the Metaphysics of Aristotle (Vol 1). Translated by Girard J. Etzkorn and Allan B. Wolter. St. Bonaventure, NY: Francsican Institute.

Economos, Ariane. 2009. Intellectus and induction: three Aristotelian commentators on the cognition of first principles, including an original translation of John Buridan's Quaestiones in duos Aristotelis libros Posteriorum Analyticorum. PhD Dissertation. New York: Fordham University.

Grellard C. 2007. 'Scepticism, demonstration and the infinite regress argument (Nicholas of Autrecourt and John Buridan). Vivarium 42: 328-342.

King, P. 2001. 'John Buridan's solution to the problem of universals'. In: J. M. M. H. Thijssen \& Jack Zupko (eds), The Metaphysics and Natural Philosophy of John Buridan. Brill, pp. 1-28

King P. 1987. 'Jean Buridan's philosophy of science'. Studies in History and Philosophy of Science 18: 109-132.

Klima, G. 2009. John Buridan, Great medieval thinkers. Oxford: Oxford University Press.

Knuuttila, S. 1990. 'Nomic necessities in late medieval thought'. In: S. Knuuttila et al. (eds), Knowledge and the Sciences in Medieval Philosophy. Proceedings of the Eighth International Congress of Medieval Philosophy II, Helsinki: Publications of Luther-Agricola Society, pp. 222-230.

Lagerlund H. (ed.) 2010. Rethinking the history of skepticism: the missing medieval background. Leiden-Boston: Brill.

Longeway J. L. 2007. Demonstration and scientific knowledge in William of Ockham: a translation of Summa Logicae III-II: De Syllogismo Demonstrativo, and selections from the Prologue to the Ordinatio. Notre Dame: University of Notre Dame Press.

McCaskey, John P. 2007. ' Freeing Aristotelian epagōgē from 'Prior Analytics II 23'. Apeiron 40: 345-374.

McGinnis, J. 2003. 'Scientific methodologies in Medieval Islam'. Journal of the History of Philosophy 41: 307-327.

Nicolaus of Autrecourt. 2010. Letters to Bernard of Arezzo. In: Arthur Hyman, James J. Walsh, and Thomas Williams (eds) Philosophy in the Middle Ages, The Christian, Islamic, and Jewish Traditions (Third Edition). Indianapolis \& Cambridge: Hackett Publishing Company, Inc., pp. 652-558.

Nicolaus of Autrecourt. 1971. The universal treatise. L. A. Kennedy, R. E. Arnold, and 
A. E. Millward transl. (an English translation of Exigit ordo executionis). Milwaukee: Marquette University Press.

Ockham, William. 2010. 'Intuitive and abstractive cognition'. In: Arthur Hyman, James J. Walsh, and Thomas Williams (eds) Philosophy in the Middle Ages, The Christian, Islamic, and Jewish Traditions (Third Edition). Indianapolis \& Cambridge: Hackett Publishing Company, Inc. pp. 624-630

Ockham, William. 1990. Philosophical writings: a selection. Trans. P. Boehner, revised edition by S. F. Brown. Indianapolis: Hackett.

Ockham William. 1974. Ockham's theory of terms: part I of the Summa Logicae. trans. M. J. Loux. Notre Dame: University of Notre Dame Press.

Pasnau, R. 2010. 'Science and certainty'. In R. Pasnau (ed.) Cambridge History of Medieval Philosophy. Cambridge: Cambridge University Press, pp. 357-68

Peter of Spain. 2014. Summaries of Logic. Text, Translation, Introduction, and Notes by Brian P. Copenhaver, Calvin G. Normore, and Terence Parsons, New York: Oxford University Press.

Rashdall, H. 1907. 'Nicholas de Ultricuria, a medieval Hume'. Proceedings of the Aristotelian Society 8: 1-27.

Raymond, Fr. 1909. 'La théorie de l'induction: Duns Scotus précurseur de Bacon'. Études Franciscaines 21: 113-126 \&270-279.

Richard, T. 1893. 'De la nature et du rôle de l'induction d'après les anciens'. Revue Thomiste 16: 301-310

Sextus Empiricus. 2000. Outlines of Scepticism. Edited by Julia Annas and Jonathan Barnes. Cambridge: Cambridge University Press.

Spade, P. V. 2000. 'Ockham's nominalist metaphysics: some main themes'. In: Spade P. V. (ed.) The Cambridge companion to Ockham. Cambridge: Cambridge University Press, pp. 100-117.

Stump, Eleonore. 2003. Aquinas. London: Routledge.

Thijssen, J. M.M. H. 1987. 'John Buridan and Nicholas of Autrecourt on causality and induction'. Traditio 43: 237-255.

Vos, Antonie. 2006. The Philosophy of John Duns Scotus. Edinburgh: Edinburgh University Press.

Weinberg, J. R. 1965. Abstraction, relation and induction. Three essays in the history of thought. Madison: The University of Wisconsin Press.

Weinberg, J. R. 1948. Nicholas of Autrecourt. A case study in fourteenth century thought. Princeton: Princeton University Press.

Wolter A. B. 1987. Duns Scotus: philosophical writings. Indianapolis: Hackett.

Zupko, J. 1993. 'Buridan and skepticism'. Journal of the History of Philosophy 31:191221. 